\title{
Firm Size Matters: Growth and Productivity Growth in African Manufacturing
}

\author{
JOHANNES VAN BIESEBROECK \\ University of Toronto and National Bureau of Economic Research
}

\section{Introduction}

The recent availability of firm- and plant-level panel data sets has greatly improved our understanding of the life cycle of firms. Several stylized facts have been established and confirmed in a number of developed countries. With time, the patterns discovered are certain to spawn new theories explaining why and how firms enter an industry, expand, and eventually are forced to exit. Most of the research has focused on the experience of firms in mature economies, with a particular emphasis on the United States. Caves (1998) summarizes the findings on turnover and mobility, and Bartelsman and Doms (2000) summarize what has been learned about the distribution and evolution of productivity.

A question remains to what extent the U.S. experience generalizes to other, especially less developed, economies. A recent survey on manufacturing firms in developing countries, Tybout (2000), summarizes the current state of knowledge. A major contribution is to dispel four pervasive myths. Relative to more developed economies, (a) there is no reason to expect less competition, $(b)$ firm turnover is equally important, $(c)$ the scope for realizing scale economies is limited, and $(d)$ dispersion of productivity is similar in developing countries. Although Tybout can draw only occasionally on evidence from sub-Saharan Africa, the findings suggest where not to look for differences between developed and developing countries.

Using a rich panel data set of manufacturing firms in nine sub-Saharan African countries, I document important differences in the evolution of the size and productivity distribution between firms in Africa and those in the

I wish to thank Marcel Fafchamps for helping me to get access to the data set. I benefited from comments by Lanier Benkard, Nancy Gallini, Peter Reiss, and Frank Wolak and am also indebted greatly to an anonymous referee and the editor for many helpful suggestions that improved the article substantially. Financial support from the Littlefield Fellowship and the Belgian American Educational Foundation is gratefully acknowledged.

(C) 2005 by The University of Chicago. All rights reserved. 0013-0079/2005/5303-0001\$10.00 
United States and other more developed countries. ${ }^{1}$ American firms follow a life cycle. Firms enter, on average, at a smaller scale and with lower productivity. Many exit shortly after entering, while the survivors quickly converge to the industry average size and productivity level. Exit from the industry by mature firms is generally preceded by a period of declining size and productivity. In Africa, however, the largest and most productive firms also display the highest growth rates and contribute disproportionately to aggregate growth. This leads to divergence between firms at the top and bottom of the distribution. Small firms rarely reach the top of the size and productivity distribution.

Given the large literature on the informal sector in developing countries, this might not come as a surprise, ${ }^{2}$ were it not that most firms in the sample, even the smaller ones, are in the formal sector. They are set up outside the household, pay taxes, invest frequently, are officially in the manufacturing sector, and have already survived for several years. Even in the formal sector firms tend to fall into two classes. Some stay small and remain vulnerable to exit. Others prosper. They invest, start exporting, and adopt new technologies.

It is often assumed that a major obstacle to expansion for firms at the bottom of the size and productivity distribution is the limited availability of credit (see Kochar [1997] for a critical assessment). While larger firms are much more likely to report having access to formal credit, credit availability is also strongly correlated with productivity. The correlation remains after controlling for firm size. Productivity growth decompositions demonstrate further that the labor market improves aggregate productivity in the economy by relocating workers from below to above average productive firms.

The remainder of the article is organized as follows. In Section II, the countries and firms are introduced, and the sampling frame is discussed. After a review of the literature in Section III, it is shown in Section IV that firm size matters a great deal in the evolution of the size and productivity distribution of African manufacturing firms. The interaction of the two factor markets with firm-level and aggregate productivity is evaluated in Section V. Conclusions are in Section VI.

\footnotetext{
${ }^{1}$ Because the data set I work with is constructed from surveys and does not cover the universe of firms, I cannot draw conclusions about the distribution of firms at a given point in time.

${ }^{2}$ See Ranis (1988) and several other chapters in the first volume of the Handbook of Development Economics.
} 


\section{Data}

A. Countries

All nine sub-Saharan countries in the sample are classified as low income by the World Bank. Gross domestic product per capita ranges from \$450 (in 1995 PPP) in Ethiopia to $\$ 2,110$ in Cameroon, which is still less than onetenth of U.S. income. Except for South Africa and Nigeria, all large economies in the region are included. Income and population statistics are in table 1.

At independence, in the 1960s, manufacturing accounted for only $9 \%$ of GDP in sub-Saharan Africa. To most observers' surprise, this increased only slightly, to $11 \%$, over the next 30 years. Economic activity in the three poorest countries-Burundi, Ethiopia, and Tanzania-is still largely geared toward agriculture, which generates more than half of GDP. Only Zambia and Zimbabwe developed an important manufacturing industry, generating around $30 \%$ of GDP. In the remaining countries-Kenya, Côte d'Ivoire, Ghana, and Cameroon-industry employs approximately $10 \%$ of the workforce and generates approximately $20 \%$ of GDP. Workers leaving agriculture often transition directly into the service sector.

The lagging industrialization is sometimes blamed for the low level of economic development in the region. Comparing the third and fourth column in table 1 reveals that the share of GDP generated by industry invariably exceeds the share of employment. Value added per worker is higher-sometimes five times as high-in industry than in agriculture or services. Expanding the manufacturing sector is certainly appealing to these countries, and a closer look at the evolution of manufacturing firms can shed light on the lack of growth in this sector.

The countries cover a wide range of macroeconomic growth experiences, varying from sustained growth in Kenya to an almost complete collapse of the economy in Zambia and everything in between. The aggregate business cycle is summarized in appendix A, which should help to put the firm-level growth rates in perspective. In the analysis, the productivity measures in all figures are relative to the median for the country-year, and all regressions include country-year dummies.

\section{B. Sampling Frame}

This article uses a firm-level data set, constructed from surveys in the manufacturing sector of nine African countries. The data collection was coordinated by the World Bank as part of its Regional Program on Enterprise Development 
TABLE 1

SUMMARY STATISTICS

\begin{tabular}{|c|c|c|c|c|c|c|c|c|c|c|c|c|}
\hline & \multicolumn{4}{|c|}{ Aggregate Economy (1995) } & \multicolumn{8}{|c|}{ Sample (First Wave of Interviews; Year Differs by Country) } \\
\hline & \multirow[b]{2}{*}{$\begin{array}{l}\text { Pop. } \\
\text { (mil) }\end{array}$} & \multirow{2}{*}{$\begin{array}{l}\text { GDP/ } \\
\text { Capita } \\
\text { (PPP) }\end{array}$} & \multicolumn{2}{|c|}{ Share of Industry } & \multirow{2}{*}{$\begin{array}{c}\text { Coverage } \\
\text { of } \\
\mathrm{GDP}^{\dagger}\end{array}$} & \multicolumn{2}{|c|}{$\begin{array}{c}\text { Employment } \\
\text { per Firm }\end{array}$} & \multirow[b]{2}{*}{$\begin{array}{l}\text { Number } \\
\text { of Firms }\end{array}$} & \multicolumn{4}{|c|}{ Frequency by Size Class } \\
\hline & & & $\ln L F^{*}$ & In GDP & & Mean & Median & & $\begin{array}{l}\text { Micro } \\
(\leq 5)\end{array}$ & $\begin{array}{l}\text { Small } \\
(6-24)\end{array}$ & $\begin{array}{c}\text { Medium } \\
(25-99)\end{array}$ & $\begin{array}{l}\text { Large } \\
(\geq 100)\end{array}$ \\
\hline Ethiopia & 56.4 & 450 & .02 & .10 & .79 & 155 & 10 & 217 & .29 & .42 & .14 & .15 \\
\hline Burundi & 6.3 & 630 & .03 & .18 & .65 & 61 & 12 & 120 & .34 & .28 & .27 & .11 \\
\hline Tanzania & 29.6 & 640 & .05 & .17 & .31 & 91 & 12 & 213 & .23 & .39 & .21 & .17 \\
\hline Zambia & 9.0 & 930 & .09 & .40 & .12 & 85 & 23 & 211 & .20 & .29 & .32 & .19 \\
\hline Kenya & 26.7 & 1,380 & .07 & .17 & .17 & 95 & 22 & 222 & .28 & .24 & .27 & .21 \\
\hline Côte d'Ivoire & 14.0 & 1,580 & .10 & .20 & .52 & 168 & 18 & 235 & .30 & .25 & .25 & .20 \\
\hline Ghana & 17.1 & 1,990 & .13 & .16 & .14 & 57 & 16 & 192 & .23 & .37 & .25 & .15 \\
\hline Zimbabwe & 11.0 & 2,030 & .08 & .36 & .26 & 292 & 90 & 199 & .05 & .25 & .23 & .47 \\
\hline Cameroon & 13.3 & 2,110 & .09 & .23 & .63 & 162 & 22 & 210 & .17 & .40 & .26 & .17 \\
\hline
\end{tabular}

Source. World Bank (1997a), World Bank (1997b), and calculations based on RPED surveys.

* Share of labor force in 1990.

† Total sample value added (VA) as percentage of manufacturing GDP. 
(RPED). In most countries, three rounds of interviews were conducted in consecutive years between 1992 and $1996 .^{3}$

The unit of observation is a firm, in contrast with most studies for developed countries that work with establishments. ${ }^{4}$ Approximately 200 firms were sampled in each country, chosen from four broadly defined sectors-food, textiles and clothing, wood and furniture, and metal and machinery. The sample was further stratified by firm size and location. A firm-based random sample would have produced a sample nearly exclusively made up of micro firms. An employment-based random sample would have included hardly any informal establishments. Therefore, it was decided to resort to disproportionate stratified sampling. A first-level stratification was done along the firm-size dimension as expressed by the number of full-time employees. ${ }^{5}$ A second-level stratification was done by geographic location.

Formal firms were generally selected from the national census of manufacturing firms or a broader industry directory. Given that this information was invariably a couple of years old, the sample is implicitly biased toward firms that have survived for a number of years. The same holds true for any empirical work in developed countries, but because the directory of existing firms is updated less frequently in developing countries, the bias is likely to be greater. ${ }^{6}$

Because the national censuses are likely to miss many informal or micro firms, the sample was supplemented with randomly selected smaller firms, consistent with the geographic and size stratification. ${ }^{7}$ The selection of informal firms was generally left to the interviewers.

No generalizations to the firm or employee population can be made from the sample, as weights were not calculated for each country. The national firm censuses were often deemed not sufficiently reliable to construct weights, for

\footnotetext{
${ }^{3}$ In Burundi only the first round was completed and in Côte d'Ivoire only the first two rounds. Data for Ethiopia were collected independent of the RPED, and we have access only to the first round of interviews.

${ }^{4}$ Many of the developing country results summarized in Tybout (2000) also rely on firm-level data. The distinction between plants and firms is less important in developing countries because the fraction of multiplant firms is negligible.

${ }^{5}$ Unfortunately, the size categories for the first stratification vary slightly by country. In most cases, four size categories are used, defined as: micro (fewer than 5 employees); small (between 5 and 25 to 50 employees, varying by country); medium (25 or 50 to 100 employees, 200 for Zimbabwe); large (more than 100 employees, 200 for Zimbabwe).

${ }^{6}$ For example, the first wave of interviews in Ghana was conducted in 1992, while sampling was based on the 1987 Census of Manufacturing Activities. In Tanzania, the first interviews were conducted in 1993, while the information in the Directory of Industries refers to enterprises that operated during the year 1989.

${ }^{7}$ The cutoff for inclusion in the national census or directory differs by country but is generally 5 (e.g., Zimbabwe) or 10 (e.g., Tanzania).
} 
example, because many sampled firms turned out to have already exited the industry.

Comparing the total value added for the sample with the manufacturing component in GDP, from World Bank (1997a), gives the percentage of manufacturing output covered by the sample. It ranges from $12 \%$ to $79 \%$, with approximately $40 \%$ of output in the nine countries combined accounted for by firms in the sample. This fraction is likely to be an overestimate, as some manufacturing establishments are bound to be missed in the official statistics. Nevertheless, the sample covers a substantial share of the total manufacturing sector.

\section{Firms and Variables}

In the first survey year, the sample draws around 200 firms from each country; exact numbers are in table 1 . Average employment by firm is 130 , and the median is 26 . Note that the stratification by size oversamples large firms and makes it impossible to infer anything about the population of firms. The median and average differ only substantially from the other countries in Zimbabwe. ${ }^{8}$

Using total employment, including full-time permanent, part-time, and seasonal workers, the distribution of firms over the micro, small, medium, and large size classes differs somewhat by country, although the frequency is close to $25 \%$ in most country categories. The largest anomaly is the undersampling of micro firms in Zimbabwe, with a corresponding oversampling of large firms (see also n. 8). In all other countries, large firms make up less than one-quarter of the sample, simply because there were too few large firms in the sampled regions. In some countries, the compensation is to a disproportionate extent toward an oversampling of small firms.

Recall questions asking about employment, production, and investment in previous years, including the start-up year, are used to extend the sample period back in time. Table B1 in appendix B lists the numbers of firms in each year for which employment is observed for at least a quarter of firms in the sample.

The principal measure of firm size used in the analysis is employment, defined as all workers, including part-time and seasonals. An alternative measure is value added, obtained by subtracting material input, energy, and in-

${ }^{8}$ In Zimbabwe, different definitions of the firm-size categories were used in the sampling stratification. The manufacturing sector in Zimbabwe is much more developed than in the other countries, and more medium and larger firms were included. The only country where industry generates a similar share of GDP is Zambia (see the fourth column of table 1), but that is misleading because of its large copper-mining sector. 
direct costs from sales. In absence of sectoral price series, nominal values are converted into real value added using the aggregate GDP deflator.

Two productivity measures are used in the analysis. Labor productivity (LP) is calculated as value added over employment. Because the recall questions ask only about employment, sales, and investment, I assume a constant value added to sales ratio to construct value added in years prior to the surveys. ${ }^{9}$ Total factor productivity (TFP) is calculated as $Y_{i t} /\left(L_{i t}^{s_{L}} K_{i t}^{1-s_{L}}\right)$. The capital stock is measured by the owner's estimate of the replacement value of the plant and equipment and $s_{L}$ is the wage share in value added, averaged by country, including payments in kind and other benefits where applicable. As a normalization, I divide by TFP for the firm with median productivity $(m)$ in the same country,

$$
\operatorname{TFP}_{i t}=\left[\frac{\frac{Y_{i t}}{Y_{m t}}}{\left(\frac{L_{i t}}{L_{m t}}\right)^{s_{L}}\left(\frac{K_{i t}}{K_{m t}}\right)^{1-s_{L}}}\right] .
$$

Caves, Christensen, and Diewert (1982) demonstrate that (1) is a valid measure of Hicks-neutral productivity change for any homogeneous of degree one translog production function, assuming profit maximization and perfect competition in factor and goods markets. ${ }^{10}$ Other variables will be discussed when they are first used in the analysis. ${ }^{11}$

\section{Previous Literature on the Evolution of Size and Productivity}

Many studies of firms in developed countries have shown that the distribution of firm size at any point in time corresponds remarkably well to predictions made by Gibrat's law of proportional effect. This states that all firms, irrespective of size, grow each year by some random draw from the distribution of growth rates. However, a lot of studies using panel data sets that allow the calculation of firm-level growth rates have found that there is a negative correlation between growth rate and size or age. Caves (1998) discusses these and some other determinants and regularities of firm-level growth.

Sleuwaegen and Goedhuys (2002) cite a large number of sources from both developed and developing countries confirming that larger and older firms

\footnotetext{
${ }^{9}$ The ratio is very stable over the three survey years for virtually all firms.

${ }^{10}$ If one uses $\left(s_{i t L}+s_{m t L}\right) / 2$ instead of $s_{L}$ as exponent in the denominator of (1), the measure is exact as defined in Diewert (1976), but it generates nontransitive TFP measures. Of all the input and output variables, the wage bill is most volatile over time and across firms, and averaging is likely to remove some measurement error.

${ }^{11}$ For a discussion of the range of topics covered in the questionnaire, see Biggs and Srivastava (1996).
} 
grow at significantly slower rates. In their own work on Côte d'Ivoire they document the missing middle in the size distribution of firms, which is also discussed by Tybout (2000), who cites evidence from several continents. Sleuwaegen and Goedhuys (2002) also find that more efficient firms tend to have higher growth rates, providing an intuitive link between the size and productivity distributions.

The book by Liedholm and Mead (1999) summarizes the results from a large body of work on the size distribution and growth rates specifically for sub-Saharan Africa. They take a novel approach by constructing an exhaustive sample of firms by visiting every house in a geographic area and collecting data whenever a business-not limited to manufacturing-is encountered. Mead $(1994,1)$ describes the sampling frame in detail. While research in developed countries is facilitated by the existence of a census of manufacturing that surveys all existing firms, most work for Africa has relied on surveys, which is less attractive to study the distribution of firms. ${ }^{12}$ One drawback is that firms with more than 50 employees are dropped. These are rare but account for a significant share of output in most countries.

Table 3 in Mead and Liedholm (1998) summarizes some crucial findings for their sample of micro and small enterprises. Small and young firms are more likely to grow. Estimation results in McPherson (1996) indicate that size and age are the two variables with most predictive power for employment growth. The results are very robust across five African countries.

Older firms, on the other hand, are less likely to exit, which is surprisingly also the case for smaller firms. In contrast, a recent paper by Frazer (2004) using a longer panel of the RPED data set for Ghana finds that large firms are significantly less likely to exit, after controlling for age and productivity level. The counterintuitive result in Mead and Liedholm (1998) is likely due to the exclusion of medium and large firms.

Productivity has not received as much attention as firm size, but some consistent patterns have emerged. Bartelsman and Doms (2000) summarize what has been learned about the distribution and growth of productivity in longitudinal microdata sets, focusing solely on work for developed countries. They report that productivity levels are very dispersed and highly persistent. Productivity growth, on the other hand, is less dispersed and much less persistent. Plants with high productivity, as measured by TFP, enjoy high growth rates of output and a higher likelihood of survival. Finally, resource reallocation

${ }^{12}$ Recent work by the U.S. Bureau of the Census highlights that even the Census is based on a business registry of firms that is inevitably at least 1 year old. More firms are missed in the Census than has been commonly assumed; see Davis et al. (2004). 
between incumbent plants is strongly efficiency enhancing for the aggregate economy.

Roberts and Tybout (1996) combine a number of studies looking at turnover and the evolution of productivity that use the census of manufacturing, that is, the universe of all plants, in developing countries. A consistent finding is that exiting and entering plants have lower productivity than incumbents (see Tybout and Liu [1996] for Chile and Colombia or Aw, Chen, and Roberts [2001] for Taiwan). The same two studies also find that the least efficient of newly entered plants is more likely to exit. Survivors converge rapidly to the average productivity level. In Latin America, this process takes only 3-4 years, while in Taiwan it is not complete after 5 years for some industries (see Tybout 2000)

Studies for Kenya and Jamaica, discussed in Mead and Liedholm (1998), find that the growth rate of sales was almost double the growth rate of employment. Moreover, the average annual employment growth rate since start-up across all six countries studied was $13 \%-16 \%$ per year. In most cases, these growth rates are at least double the rate of growth in GDP. Assuming that the ratio of value added to sales is relatively constant over time, this points to rapid labor productivity growth in surviving entrants.

Not only the location but also the shape of the size and productivity distributions change over time. Dispersion within each cohort falls when firms age and some exit (see Caves 1998). Griliches and Mairesse (1983) find further that in the United States and France the variance of firm-level growth rates decreases with size and age. In contrast, Griliches and Regev (1995) find higher labor productivity growth rates for larger firms in Israel. The left tail of the distribution disappears because of exit and convergence. Mean reversion effects also reduce the right tail (see Griliches and Mairesse [1983], who find that productivity growth is negatively correlated with the productivity level, and Baily, Hulten, and Campbell [1992], who show that productivity growth is negatively correlated with productivity growth 5 years ago). As a result, the distribution of incumbents is relatively symmetric.

The picture of the evolution of firms that emerges looks like this: newly entered firms are smaller and have below average productivity. Exit rates are large for recent entrants, but those that survive converge rapidly to the industry average, enjoying higher growth rates in size and productivity. At any point, larger ${ }^{13}$ older, and more productive firms are less likely to exit. Before exiting, firms experience a number of years of negative productivity growth, which

${ }^{13}$ Except for small and medium sized firms in Africa, where the probability of survival is Ushaped. 
Griliches and Regev (1995) have dubbed "the shadow of death." Even among firms of similar size and age productivity dispersion is typically very large, but it falls as cohorts age. Relocation of resources is a crucial determinant of aggregate TFP growth (see Baily et al. [1992] and Bartelsman and Dhrymes [1998] for U.S. results and Levinsohn and Petrin [1999] for Chile).

\section{The Evolution of Size and Productivity in Africa}

\section{A. Large Firms Are More Productive}

While size and productivity evolve according to a life cycle in more developed economies, in Africa size is unusually important for success. The first aspect of this is the significantly higher productivity attained by large firms; the productivity distribution differs more by size class than by age group. Figures 1 and 2 illustrate the productivity distribution for firms of different groups. Graphs on the left plot the probability density; the cumulative distribution is on the right.

Graphs in the top row of figure 1 show that labor productivity for firms that exist 20 or more years is noticeably higher than for firms in the other age groups. The mode of the distribution shifts slightly to the right as firms age, the left tail shrinks, and the distribution becomes taller. The distribution of firms 6-19 years old differs in a similar fashion from the two groups of even younger firms, but the differences are less pronounced. While younger firms are only marginally less productive, their productivity is notably more dispersed, especially at the bottom.

The cumulative distribution for $20+$ year old firms, on the right, lies below all other distributions at each point, indicating first-order stochastic dominance. For successively younger groups of firms the distribution shifts gradually upward, but the difference is never as big as for the oldest group of firms.

Differences between the four age groups are even smaller for the TFP distribution. The higher LP for older firms is to a large extent due to accumulated capital. Both the increase in productivity and the reduction in variance when firms age is diminished. The mode of the oldest group of firms is still a bit higher, but all other groups are similar. It takes a very long time before the productivity of incumbents can be distinguished from newer entrants in Africa. In contrast, Baily et al. (1992) find that in the United States it takes entrants only 10 years to fully converge to the industry average productivity level, and it takes even less time in Latin America or Taiwan, as discussed in the previous section.

$P$-values for two different tests whether two independent samples (i.e., for unmatched data) come from populations with the same distribution are in table 2. Results for the Wilcoxon (Mann-Whitney) rank-sum test are in the 

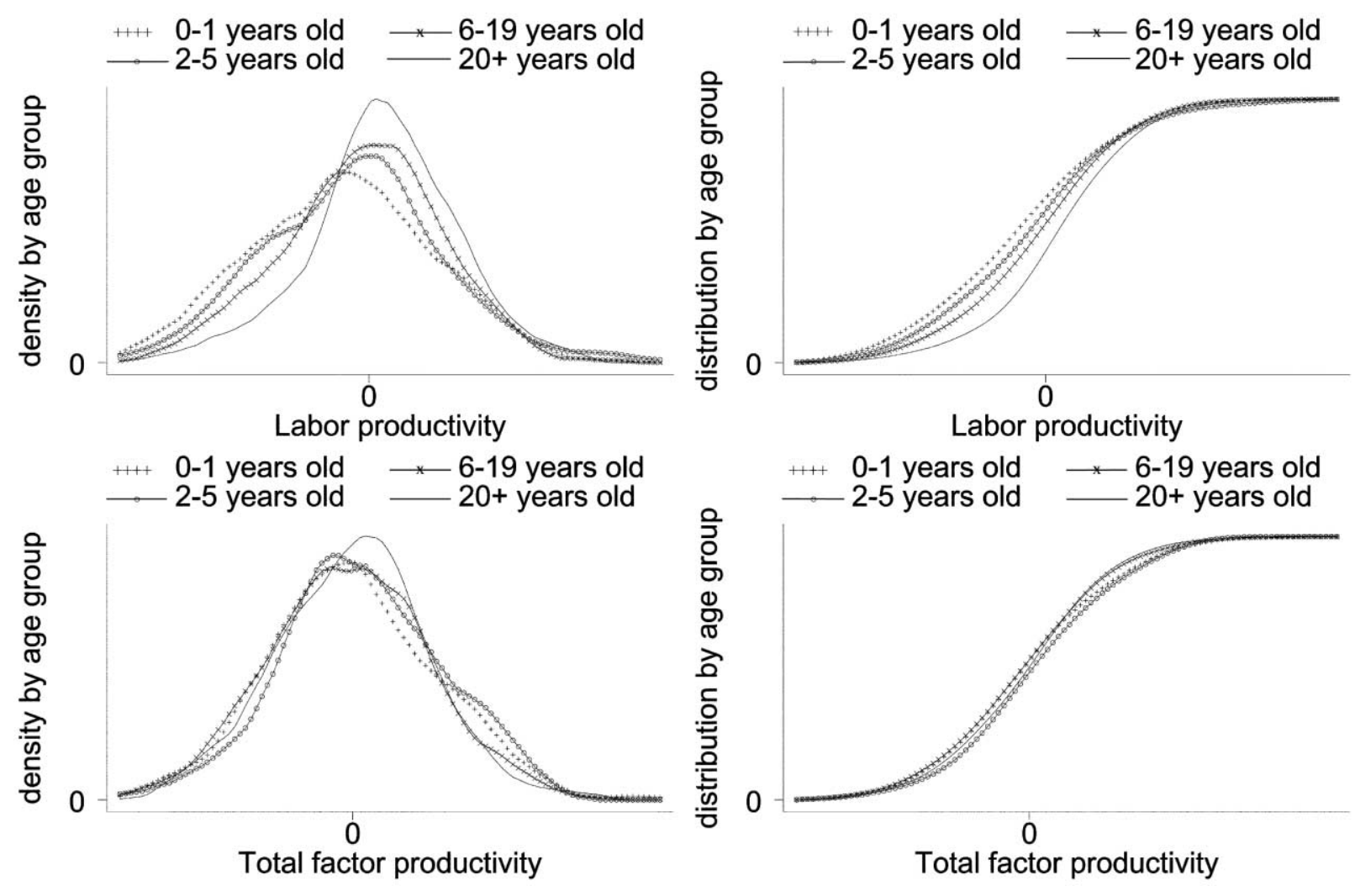

Total factor productivity

Figure 1. Productivity density and distribution by age group 


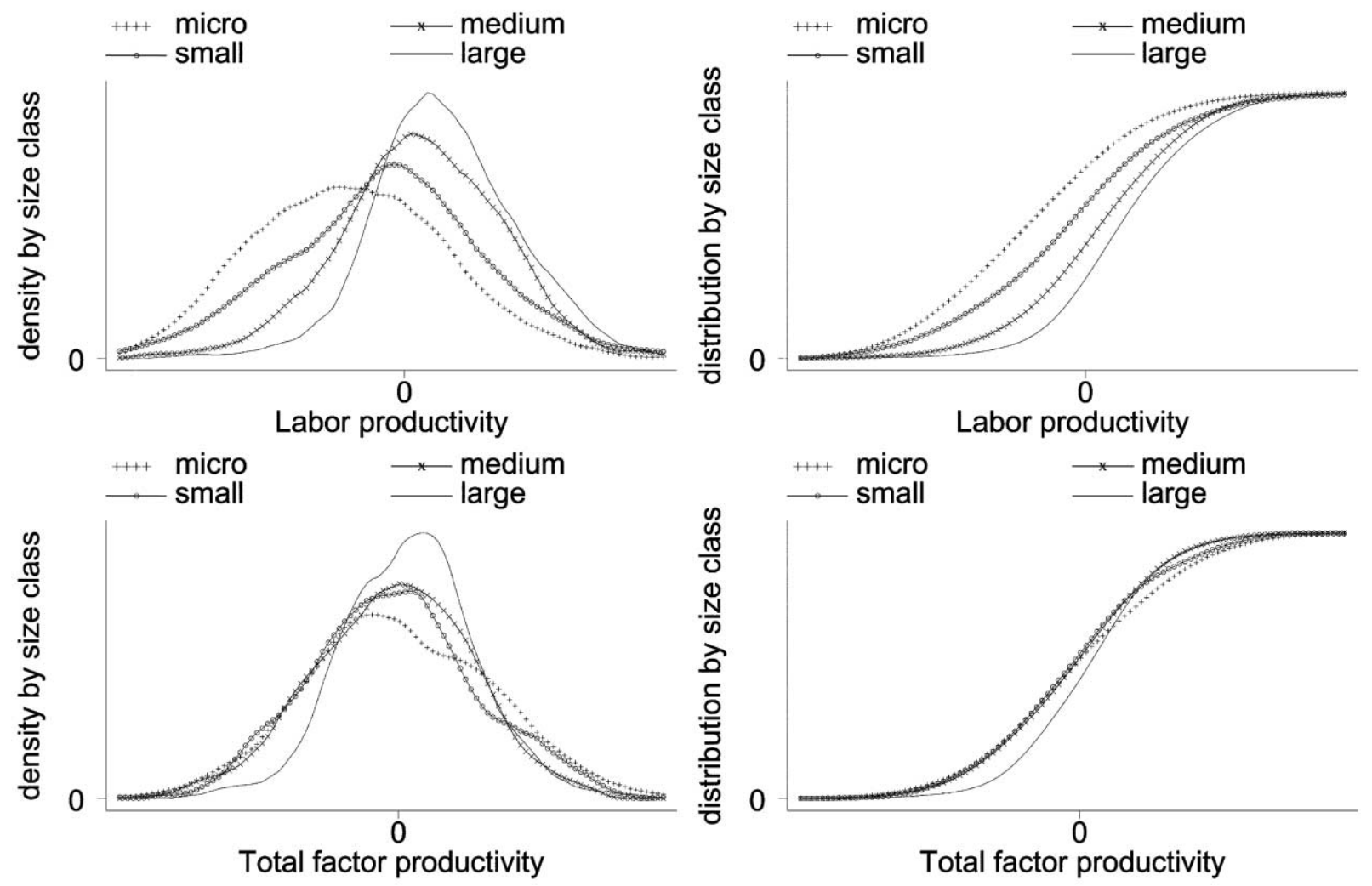

Figure 2. Productivity density and distribution by size class 
TABLE 2

TESTS FOR EQUALITY OF THE DISTRIBUTIONS BY AGE GROUP (P-VALUES)

\begin{tabular}{|c|c|c|c|c|c|c|c|c|}
\hline \multirow[b]{2}{*}{ Age } & \multicolumn{4}{|c|}{ Labor Productivity } & \multicolumn{4}{|c|}{ Total Factor Productivity } \\
\hline & $0-1$ & $2-5$ & $6-19$ & $20+$ & $0-1$ & $2-5$ & $6-19$ & $20+$ \\
\hline $0-1$ years & $\ldots$ & .262 & .001 & .000 & $\ldots$ & .199 & .538 & .338 \\
\hline $2-5$ years & .187 & $\ldots$ & .054 & .000 & .162 & $\ldots$ & .080 & .145 \\
\hline $6-19$ years & .001 & .029 & $\ldots$ & .000 & .562 & .011 & $\ldots$ & .438 \\
\hline $20+$ years & .000 & .000 & .000 & $\ldots$ & .976 & .072 & .459 & $\ldots$ \\
\hline
\end{tabular}

Note. The $P$-values in the bottom left of each quadrant refer to the two-sample Wilcoxon rank-sum (Mann-Whitney) test, for the hypothesis that two independent samples (i.e., unmatched data) are from populations with the same distribution. The $P$-values in the upper right of each quadrant are for the Kolmogorov-Smirnov equality of distributions test.

upper right of each quadrant and for the Kolmogorov-Smirnov equality of distributions test in the bottom left. The tests confirm the previous inferences. The LP distribution of the oldest group of firms $(20+$ years) is significantly different from each of the three other groups. The LP distribution for firms 6-19 years old differs from the two younger groups, but only at a 5\% significance level. For TFP, only the Wilcoxon test suggests that firms between 2 and 5 years old come from a different distribution than the older firms. No other distributions differ.

Graphs in figure 2 compare the productivity distributions for firms of different sizes. ${ }^{14}$ The distribution of larger firms differs from that of smaller firms in a way similar to that of older firms differing from younger ones, but the differences are much larger.

The productivity distribution shifts gradually to the right for each larger size class. The shift is especially pronounced for LP and for micro firms, but it holds throughout, even for TFP. The very high levels of TFP achieved by some micro firms is an artifact of using the same input shares for all firms, even though some micro firms operate with hardly any capital. The gradual thickening of the left tail and the increase of dispersion for smaller firms are very pronounced for LP and remain for TFP. Both differences are larger than those by age group.

The cumulative distributions for each of the four size classes, on the right, are clearly separated for LP. For each group of firms the distribution of LP first-order stochastically dominates productivity for smaller firms. Controlling for capital intensity, the TFP distribution for the largest firms, those employing 100 or more workers, is still visibly different.

Formal tests for differences in distribution by size class, in table 3, leave little room for doubt. Equality of the productivity distributions for large firms

${ }^{14}$ Throughout, the same size classes that underlie the sampling scheme are used; see n. 5 above and table 1. 
TABLE 3

TESTS FOR EQUALITY OF THE DISTRIBUTIONS BY SIZE CLASS (P-VALUES)

\begin{tabular}{|c|c|c|c|c|c|c|c|c|}
\hline \multirow[b]{2}{*}{ Size } & \multicolumn{4}{|c|}{ Labor Productivity } & \multicolumn{4}{|c|}{ Total Factor Productivity } \\
\hline & Micro & Small & Medium & Large & Micro & Small & Medium & Large \\
\hline Micro & $\ldots$ & .000 & .000 & .000 & $\ldots$ & .108 & .076 & .001 \\
\hline Small & .000 & $\ldots$ & .000 & .000 & .401 & $\ldots$ & .486 & .000 \\
\hline Medium & .000 & .000 & $\ldots$ & .000 & .514 & .735 & $\ldots$ & .003 \\
\hline Large & .000 & .000 & .000 & $\ldots$ & .067 & .001 & .006 & $\ldots$ \\
\hline
\end{tabular}

Note. The $P$-values are the same as in table 2.

with all other groups can be resoundingly rejected using both productivity measures and both tests. For LP, each size class has a significantly different distribution. The $P$-values are clearly much lower than for the tests by age group.

Note that equation (1) for TFP assumes constant returns to scale, while figure 2 shows that the median productivity for micro and small firms is lower. Methods that measure productivity allowing for variable returns to scale require the separate estimation of scale economies or the calculation of a user's cost of capital, both of which are beyond the scope of this article. Accounting carefully for endogeneity problems in the production function, Söderbom and Teal (2004) cannot reject constant returns to scale in Ghana. It is also clear that firm-level variation dominates the effect of any scale economies. Thirtyfive percent of the micro enterprises, and even more small enterprises, have higher TFP than the median large firm. While it is difficult to identify scale economies separately from a productivity advantage for large firms, both allow a firm to produce more output from the same amount of inputs. ${ }^{15}$

\section{B. Large Firms Are More Likely to Survive}

Another comparison is between firms at different points in their life cycle. In figure 3, graphs in the first row plot the density and distribution of size, measured by employment, for average, entering, and exiting firms. The next two rows plot the corresponding distributions for LP and TFP. The first wave

${ }^{15}$ As a robustness check I estimate the following production function with country-year fixed effects:

$$
\ln \frac{Y}{L}=\alpha_{k} \ln \frac{K}{L}+\left(\alpha_{l}+\alpha_{k}-1\right) \ln L+\omega_{c t}+\epsilon
$$

A positive labor coefficient indicates increasing returns to scale (RTS), and it was estimated to be 0.14 (0.072). This just exceeds the range of RTS estimates that Tybout (2000) cites based on studies from Asia, Latin America, and northern Africa (0.05-0.10) or the 0.04 to 0.13 range in Söderbom and Teal (2004). TFP calculated from the residual of this equation is lower for large and medium-sized enterprises, but the median for each of these size classes still exceeds the median productivity in the sample. 


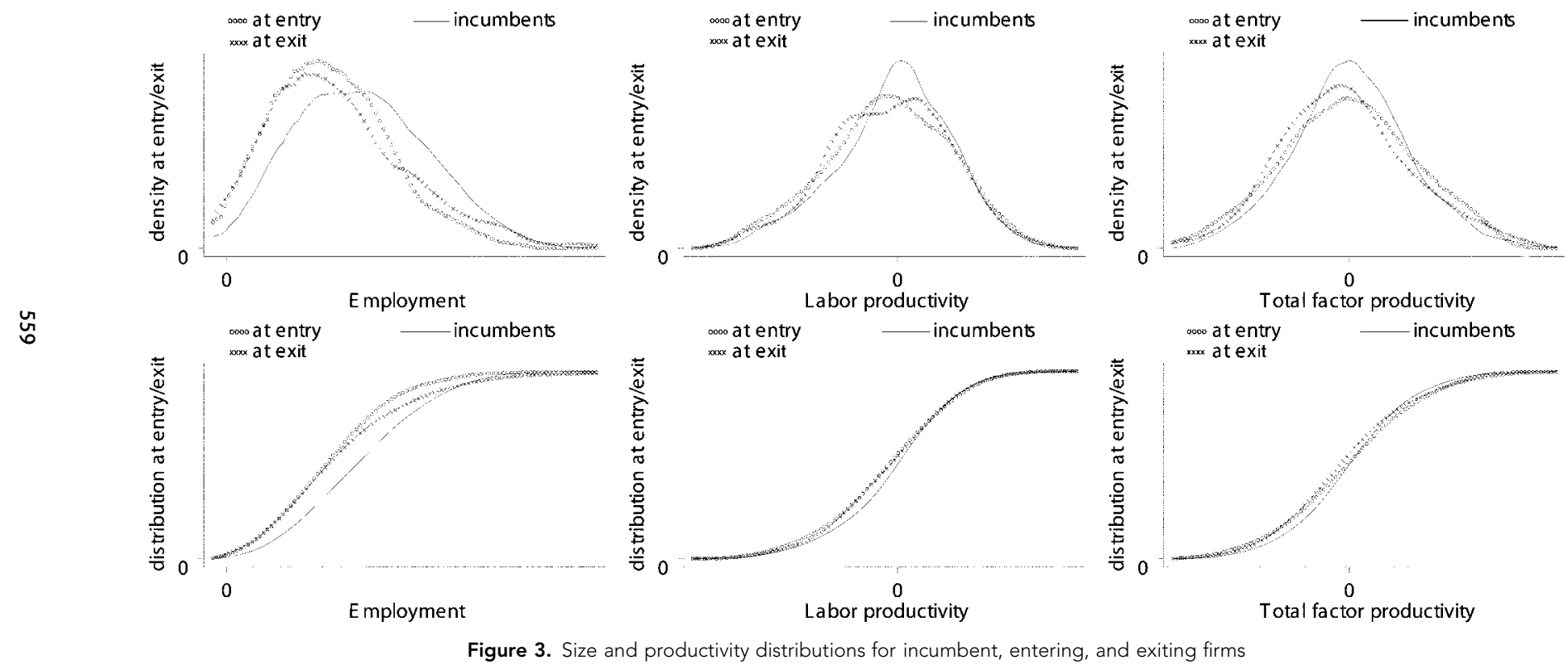


TABLE 4

TESTS FOR EQUALITY OF THE DISTRIBUTIONS BY STATUS (P-VALUES)

\begin{tabular}{|c|c|c|c|c|c|c|c|c|c|}
\hline \multirow[b]{2}{*}{ Status } & \multicolumn{3}{|c|}{ Employment } & \multicolumn{3}{|c|}{ LP } & \multicolumn{3}{|c|}{ TFP } \\
\hline & Incumbent & Entry & Exit & Incumbent & Entry & Exit & Incumbent & Entry & Exit \\
\hline Incumbents & $\ldots$ & .000 & .000 & $\ldots$ & .004 & .000 & $\ldots$ & .000 & .005 \\
\hline New entrant & .000 & $\ldots$ & .082 & .094 & $\ldots$ & .658 & .004 & $\ldots$ & .542 \\
\hline Exiting firm & .000 & .109 & $\ldots$ & .015 & .580 & $\ldots$ & .006 & .937 & $\ldots$ \\
\hline
\end{tabular}

Note. The $P$-values are the same as in table 2.

of interviews for firms that report to have entered more than 1 year ago is considered to be the average distribution (for the stratified sample). Survey questions asking about start-up year and initial employment and sales allow the calculation of size and LP at entry. The absence of capital information in the years prior to the surveys limits the group of entrants in the TFP comparison to those firms that entered at the latest in the year prior to the survey period. Note that only entrants that survive at least until the first interview can be included, implicitly conditioning on successful entrants, as discussed in the data section. For firms that exit the sample the next period, the size distribution in the year prior to exit is plotted. ${ }^{16}$

Exiting firms and, especially, entrants employ fewer workers than incumbents. This confirms findings for other countries: firms enter small, and large firms are less likely to exit. For example, Mead and Liedholm (1998) show that in five sub-Saharan African countries $22 \%-44 \%$ of micro and small enterprises started out as a single-person firm. Frazer (2004) explores the characteristics of exiting firms in Ghana in greater detail and confirms the size effect. Formal tests for equality of the distributions, in table 4, indicate clearly that incumbents are drawn from a different size distribution.

The differences in the productivity distributions are similar, but not nearly as large. Incumbents are only slightly more productive, and the left tail is only slightly smaller. The larger difference is in the variance: incumbents come from a more compact, less dispersed distribution, consistent with results in Caves (1998). Results for LP and TFP are similar. A robustness check using regression analysis confirms the positive relationship between size and productivity and the negative relationship between size and exit or entry (results are reported in app. C).

Both measures of productivity are positively correlated with size. The effect on LP is particularly important, while TFP is significantly higher only for

${ }^{16}$ Exit can have many causes. A detailed analysis of the sample construction for Tanzania (see Center for International Business Research 1997) reveals that about half of the firms that exited from the sample did so because of bankruptcy or moving, the same reasons that firms disappear from the U.S. census. 
firms that employ more than 100 workers. While age is positively correlated with LP, the relationship with TFP is negative, reflecting the effect of capital accumulation. Entrants and exiting firms have lower productivity than the youngest group of incumbents, but the differences are relatively small. For TFP the differences vanish if one compares entrants or exiting firms to any of the older groups of firms. For LP the differences remain, but they are dwarfed by the size effects.

Employment is strongly correlated with age. Entrants employ only half as many workers as 1-year-old firms. Firms that exist for more than 20 years employ three times as many workers as firms aged 1-5 years and twice as many as firms aged 6-19 years. Exiting firms, on the other hand, are 20\% smaller than survivors of the same age.

\section{Large Firms Grow Larger and Improve Productivity Faster}

The evolution of the size and productivity distribution can be studied more directly by looking at growth rates. The results in table 5 illustrate which characteristics are consistently associated with higher growth rates. Continuous variables are converted to dummies by comparing firms to the median; for example, a firm is "young" if it is younger than the median firm in the sample.

Only two variables come up with a positive sign in each of the four regressions, with year-on-year growth in employment, value added, LP, and TFP as dependent variables. Firms that operate a formal training program or that introduce new technology regularly hire more workers, produce more output, and increase output faster than inputs, although the effects are relatively small and often not significantly different from zero. As growth in value added and employment enter productivity growth with opposite signs, the ambiguous results are not unexpected.

A number of relatively robust results are worth highlighting. The wood and metal sectors have higher employment growth, which is a bit surprising as one would expect that the comparative advantage of these African countries is in food (the omitted sector) or textiles. No sectoral differences in productivity growth are apparent. Firms located in the capital city, generally the manufacturing center of the country, do not grow faster in size or productivity.

As in developed countries, younger firms are rapidly growing in size, both in terms of employment or value added, converging to the average. In contrast, no similar convergence in productivity is taking place. This could be expected as there is not much of a productivity gap between age groups (see fig. 1) or between entrants and incumbents (see fig. 3).

More surprisingly, large and medium sized firms are expanding their workforce more rapidly than smaller firms, even though they already are much 
TABLE 5

CHARACTERISTICS CORRELATED WITH GROWTH RATES

\begin{tabular}{|c|c|c|c|c|}
\hline & \multicolumn{2}{|c|}{ Size } & \multicolumn{2}{|c|}{ Productivity } \\
\hline & Employment & Value Added & LP & TFP \\
\hline \multirow[t]{2}{*}{ Textiles/garments sector } & .0057 & -.0018 & -.0057 & -.0824 \\
\hline & $(.0122)$ & $(.0269)$ & $(.0278)$ & $(.0936)$ \\
\hline \multirow[t]{2}{*}{ Wood/furniture sector } & $.0291 \star \star$ & .0181 & -.0069 & -.1057 \\
\hline & $(.0128)$ & $(.0282)$ & $(.0292)$ & $(.0960)$ \\
\hline \multirow{2}{*}{ Metal working sector } & $.0211^{\star}$ & .0020 & -.0102 & -.0877 \\
\hline & $(.0125)$ & $(.0274)$ & $(.0284)$ & $(.0915)$ \\
\hline \multirow[t]{2}{*}{ Located in capital city } & .0131 & -.0199 & -.0313 & -.0222 \\
\hline & $(.0095)$ & $(.0207)$ & $(.0214)$ & $(.0672)$ \\
\hline \multirow[t]{2}{*}{ Young firm } & $.0976^{\star \star \star}$ & $.1055^{\star \star \star}$ & .0026 & -.0131 \\
\hline & $(.0095)$ & $(.0209)$ & $(.0216)$ & $(.0725)$ \\
\hline \multirow[t]{2}{*}{ Medium/large firm } & $.0944^{\star \star \star}$ & .0224 & $-.0773^{\star \star \star}$ & 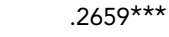 \\
\hline & (.0105) & $(.0231)$ & $(.0239)$ & $(.0800)$ \\
\hline \multirow[t]{2}{*}{ Exporter } & -.0118 & $.0487^{\star}$ & $.0565^{\star \star}$ & .1277 \\
\hline & $(.0121)$ & $(.0263)$ & $(.0272)$ & $(.0900)$ \\
\hline \multirow[t]{2}{*}{ (Partially) foreign owned } & -.0181 & $.0534^{\star}$ & $.0714^{\star \star \star}$ & .0596 \\
\hline & $(.0128)$ & $(.0282)$ & $(.0292)$ & $(.0961)$ \\
\hline \multirow[t]{2}{*}{ (Partially) state owned } & $-.0715^{\star \star \star}$ & -.0488 & .0130 & -.1361 \\
\hline & $(.0172)$ & $(.0382)$ & $(.0395)$ & $(.1421)$ \\
\hline \multirow[t]{2}{*}{ Formal training program } & $.0243^{\star}$ & .0414 & .0193 & .0368 \\
\hline & $(.0136)$ & $(.0294)$ & $(.0305)$ & $(.0940)$ \\
\hline \multirow[t]{2}{*}{ Introduced new technology } & .0021 & .0260 & .0242 & .0919 \\
\hline & $(.0106)$ & $(.0232)$ & $(.0241)$ & $(.0797)$ \\
\hline \multirow[t]{2}{*}{ High $\mathrm{K} / \mathrm{L}$ ratio } & $-.0776^{\star \star \star}$ & -.0283 & $.0504^{\star \star}$ & $-.6507^{\star \star \star}$ \\
\hline & $(.0096)$ & $(.0209)$ & $(.0216)$ & $(.0694)$ \\
\hline \multirow[t]{2}{*}{ Occasional investments } & $.0528^{\star \star \star}$ & $.0667^{\star \star \star}$ & .0204 & $-.1508^{\star}$ \\
\hline & $(.0112)$ & $(.0251)$ & $(.0260)$ & $(.0896)$ \\
\hline \multirow[t]{2}{*}{ Yearly investments } & $.0897^{\star \star \star}$ & $.1373^{\star \star \star}$ & .0559 & -.0541 \\
\hline & $(.0219)$ & $(.0476)$ & $(.0493)$ & $(.1619)$ \\
\hline \multirow[t]{2}{*}{ Constant } & $-.0809 \star \star \star$ & $-.1625^{\star \star \star}$ & $-.0847^{\star}$ & -.1784 \\
\hline & (.0198) & $(.0436)$ & $(.0451)$ & $(.1446)$ \\
\hline Number of observations & 7,389 & 6,229 & 6,229 & 1,891 \\
\hline Adjusted $R^{2}$ & .078 & .057 & .030 & .320 \\
\hline
\end{tabular}

* Significant at the $10 \%$ level.

$\star \star$ Significant at the $5 \%$ level.

$\star \star \star$ Significant at the $1 \%$ level.

larger than the average firm in these countries. No corresponding growth premium for value added exists, which results in negative labor productivity growth. The growth of TFP, on the other hand, is significantly higher for this group of firms. The difference between the LP and TFP results can be partly explained by more rapid capital accumulation in smaller firms, which start from a low base. It is partially due to a different, smaller sample. ${ }^{17}$ Running the same regressions separately by country reveals that in seven of the nine

${ }^{17}$ Only firms that were interviewed more than once can be included in the last column, as no recall information is available on the capital stock. All firms from Burundi and Ethiopia had to be dropped. 
countries the growth rate of employment and value added is higher than average for large firms. The coefficients for young and large/medium firms are among the largest effects in table 5 . The effect of age and size will be explored further in table 6 .

Exporters and firms with some foreign ownership enjoy faster growth in value added without corresponding employment growth, leading to significantly higher LP growth and somewhat higher TFP growth. Van Biesebroeck (2003) explores this issue and finds evidence of learning effects related to exporting. Firms with some state ownership are reducing employment but are hardly less expansionary in terms of value added or productivity than privately owned firms, contrary to widespread belief.

Finally, five variables related to human and physical capital have a positive effect on LP growth and are often correlated with higher employment growth as well. Employee training programs and frequent introductions of new technology have already been mentioned. Their effect on TFP growth is relatively large but estimated imprecisely. Firms that operate with a large capital stock per employee tend to reduce employment, relative to the average, but LP growth is higher. Making occasional investments in physical capital is associated with higher than average growth rates in employment, value added, and LP. The effects almost double in size if investments are made consistently in each year. Firms with high levels of capital or investment achieve lower TFP growth. Still, Bigsten et al. (2000) find that the return to capital investments in four of the countries averages $23 \%$ and exceeds the return to education by a wide margin.

The high covariance between the different measures in table 5 raises standard errors and results in few significant coefficients. Many characteristics associated with growth are found together. For example, firms with an employee training program are also more likely to introduce technology or invest regularly. Each of these activities is more likely for large firms, exporters, and foreign-owned firms.

I focus on the most surprising result, the positive coefficient on firm size in three of the four regressions, as this is in marked contrast with some of the previous literature. For the United States and France, Griliches and Mairesse (1983) find a negative correlation between size and productivity growth. In a sample of micro and small enterprises in sub-Saharan Africa, Mead and Liedholm (1998) find an inverse relationship between size and survival or the rate of employment growth. These findings are mirrored in McPherson (1996), who also documents an inverse relationship between age and growth rates using the same data set. In a review article on small enterprises and growth, focusing mostly on results for India, Donald Mead writes: "Throughout this 
TABLE 6

GROWTH BY SIZE CLASS AND AGE GROUP

\begin{tabular}{|c|c|c|c|c|c|c|c|c|}
\hline \multirow[b]{2}{*}{$\overline{\Delta \log y_{t}}$} & \multicolumn{2}{|c|}{ Employment } & \multicolumn{2}{|c|}{ Value Added } & \multicolumn{2}{|c|}{ LP } & \multicolumn{2}{|c|}{ TFP } \\
\hline & (1) & (2) & (1) & (2) & (1) & (2) & (1) & (2) \\
\hline \multirow[t]{2}{*}{ Small } & $-.081^{\star \star \star}$ & $.066^{\star \star}$ & .001 & $.111^{\star}$ & $.089^{\star \star}$ & .077 & $.279^{\star \star}$ & $.232^{\star}$ \\
\hline & $(.024)$ & $(.028)$ & $(.041)$ & (.063) & $(.043)$ & (.053) & $(.136)$ & (.141) \\
\hline \multirow[t]{2}{*}{ Medium } & $-.106^{\star}$ & $.143^{\star \star \star}$ & -.061 & $.122^{\star}$ & .043 & .049 & .215 & .137 \\
\hline & $(.025)$ & (.034) & $(.042)$ & (.070) & $(.045)$ & $(.052)$ & (.143) & (.151) \\
\hline \multirow[t]{2}{*}{ Large } & $-.140^{\star \star \star}$ & $.221^{\star \star \star}$ & -.056 & $.246^{\star \star \star}$ & .063 & $.116^{\star \star}$ & 181 & .142 \\
\hline & $(.027)$ & (.050) & $(.045)$ & (.085) & (.048) & (.055) & (.154) & (.163) \\
\hline \multirow[t]{2}{*}{$6-19$ years old } & & .012 & & .117 & & .089 & & -.025 \\
\hline & & (.065) & & (.136) & & (.114) & & $(.122)$ \\
\hline \multirow[t]{2}{*}{$20+$ years old } & & .035 & & .173 & & .129 & & -.074 \\
\hline & & $(.067)$ & & (.139) & & (.115) & & (.145) \\
\hline Lagged $y_{t-6}$ & & $\begin{array}{l}-.062^{\star \star \star} \\
(.010)\end{array}$ & & $\begin{array}{c}-.058^{\star \star \star} \\
(.011)\end{array}$ & & $\begin{array}{c}-.036^{\star \star \star} \\
(.010)\end{array}$ & & $\begin{array}{r}-.027 \\
(.032)\end{array}$ \\
\hline Observations & 1,724 & 1,078 & 1,635 & 898 & 1,635 & 898 & 787 & 728 \\
\hline Adjusted $R^{2}$ & .028 & .042 & . 028 & .053 & . 015 & .034 & . 028 & .033 \\
\hline
\end{tabular}

* Significant at the $10 \%$ level.

** Significant at the $5 \%$ level.

Significant at the $1 \%$ level. 
discussion - and indeed throughout the book-one of the most striking findings is the insignificance of firm size as an economic variable. The analysis found that in most respects the small enterprises $(<50)$ are not significantly different from the medium and large producers" (Mead 1991, 4).

Results in table 6 are for regressions with the average growth rate over the survey period as dependent variable and size dummies with controls as explanatory variables. Averaging reduces the impact of measurement error and makes the sample more alike for each of the four dependent variables. The size and age dummies are defined based on the firm's size in the first year of interviews.

Including only country location and industry dummies as controls, initial size is negatively correlated with employment growth, in line with previous findings. The correlation between value added growth and size is insignificantly negative. Size is positively related to both measures of productivity growth. The effects are large for each size category but significantly different from zero only for small firms. Note that defining size based on the first survey year biases the findings toward finding a negative correlation for employment growth and, to a lesser extent, toward a positive correlation for productivity growth. Two robustness checks are performed: (1) defining size based on employment 6 years before the first survey and (2) calculating the growth rates of the dependent variable using only the second and third survey year. The results go through qualitatively unchanged, although the smaller sample size increases the standard errors.

Without age controls, the life cycle effects documented earlier dilute the size effect as younger firms tend to be smaller and grow more rapidly. To control for a firm's history more generally, I include the level of the dependent variable 6 years prior to the survey period as explanatory variable in addition to age dummies. The lagged levels are negatively correlated with the growth rates for each of the four dependent variables. They even absorb much of the age effect as younger firms tend to be smaller and less productive. Firms with high employment or value added 6 years ago expand the workforce or value added more slowly. Firms with higher than average levels of productivity in the past tend to have lower productivity growth. These effects are consistent with convergence-laggards catch up with the leaders—or with regression to the mean.

Conditional on the past levels and age effects, large firms have higher growth rates for each of the four dependent variables. The effects are especially large for growth in employment and value added, indicating a growth premium of more than $20 \%$ for the largest firms. Size effects are estimated positive for both productivity measures as well but significant only for the comparison 
TABLE 7

SIZE AND PRODUCTIVITY DISTRIBUTION TRANSITIONS FROM BIRTH

\begin{tabular}{|c|c|c|c|c|c|}
\hline \multirow[b]{2}{*}{ Size at Start-up } & \multicolumn{5}{|c|}{ Last Available Period (Mostly 1994) } \\
\hline & Micro & Small & Medium & Large & Total \\
\hline \multirow[t]{2}{*}{ Micro } & .19 & .16 & .06 & .01 & .42 \\
\hline & (7) & (9) & (16) & (18) & (9) \\
\hline \multirow[t]{2}{*}{ Small } & .03 & .17 & .11 & .03 & .34 \\
\hline & (12) & (9) & (13) & (17) & (12) \\
\hline \multirow[t]{2}{*}{ Medium } & $<.01$ & .03 & .09 & .05 & .18 \\
\hline & (9) & (13) & (11) & (19) & (13) \\
\hline \multirow[t]{2}{*}{ Large } & $<.01$ & $<.01$ & .01 & .05 & .06 \\
\hline & (19) & $(22)$ & (15) & (16) & (16) \\
\hline \multirow[t]{2}{*}{ Total } & .23 & .36 & .26 & .15 & \\
\hline & (8) & (9) & (13) & (17) & (11) \\
\hline
\end{tabular}

Note. Each cell contains the percentage of firms that started in the size class of the row and reached the size class of the column at the end of the sample period. The "Total" column and row give the size distribution at start-up and at the end. (Median age for the firms in each cell is in brackets.)

between small and micro firms (LP) or large and micro firms (TFP). In the TFP regression, the lagged level refers to the first survey year-the first year for which the capital stock is available-and the dependent variable is the growth rate between the second and third survey years. In the smaller sample standard errors are higher, but this has the benefit of avoiding the built-in correlation between the size dummies and the TFP growth rates (as in the second robustness check above).

In summary, unconditionally, size is negatively correlated with employment growth, uncorrelated with value added growth, and positively correlated with productivity growth. Conditional on a rich group of firm characteristics, the correlation with employment growth turns positive, but it turns negative for LP growth. Conditional on age and the size or productivity level 6 years ago, larger firms unambiguously grow more rapidly and improve productivity faster.

\section{Large Firms Remain Large}

In the previous sections it was shown that large firms are more productive and that they improve productivity at faster rates. Now I ask the question, how did firms get there? Did they start out large and productive or did they move up in the distribution over time? New entrants moving up in the distribution was found to be an important source of aggregate growth in the United States.

A first set of results, in table 7, compares the size of firms at entry with their size in the last year they are observed. The bottom row indicates the fraction of firms in each size class at the end of the sample period, which is approximately 0.25 for each category by construction, except for the undersampling of large and oversampling of small firms, as discussed earlier. The 
column on the right indicates that the size distribution at entry was more heavily weighted toward micro firms.

While only $23 \%$ of the sample employ five or fewer employees, $42 \%$ of the sampled firms entered in the micro category. This mirrors findings in developed countries that firms predominantly enter small. Because of the inherent bias toward success in the sample, the share of micro firms in the population of entrants is likely to be much higher. ${ }^{18}$

Forty percent of the micro entrants still employ fewer than five workers at the end of the sample. The majority of firms that grew beyond the fiveemployee limit remained small. Only $7 \%$, one-sixth of the micro entrants, grew to the medium or large category. Equally important is the large amount of time it takes micro entrants to break the 25 -employee limit. While micro firms that grow small are on average 9 years old, it takes almost twice as long to reach the next size category. Small firms that grow medium or large are also much older (13 or 17 years) than those that remain small (9 years).

At the other extreme of the size distribution, transitions are equally rare. Only one-sixth of firms that entered with more than 100 employees saw employment contracting to below this limit. Fifty percent of small or medium firms remain in the same category throughout. Both types of firms are more likely to grow larger than to shrink, but the transitions to larger categories are very infrequent and take an especially long time. Firms that eventually become large are almost 20 years old.

The recent past illustrates that, except for Kenya, every country in the sample experienced a major economic decline in the last 15 years (see fig. A1 in app. A). Even relatively more prosperous countries, like Cameroon, Zimbabwe, or Côte d'Ivoire, lost more than $20 \%$ of output in real terms during a major recession. Smaller firms tend to suffer most during declines and, combined with the slow transition rates, it is unlikely that smaller firms reach a more sustainable size before a recession wipes them out. Slow transitions contribute to the larger firm turnover in developing countries, noted by Tybout (2000).

The comparable transition rates between productivity quartiles indicate that the distribution is least mobile at both extremes. The probability that the least or most productive firms remain in the same productivity quartile is $52 \%$. For the second and third quartile the probabilities are lower: $40 \%$ and $36 \%$.

${ }^{18}$ For example, Mead and Liedholm (1998) estimate that $78 \%$ of firms that employ fewer than 50 workers started as single worker firms. In our sample, we inevitably miss all firms that exit between the establishment of the business registers and the first year of interviews. This is likely to entail a selection, especially for the included micro and small firms. 
TABLE 8

TRANSITIONS BETWEEN SIZE CATEGORIES OVER 4- AND 8-YEAR INTERVALS (PERCENTAGES)

\begin{tabular}{|c|c|c|c|c|c|c|c|c|c|c|c|}
\hline \multirow[b]{2}{*}{ Period 1} & \multicolumn{5}{|c|}{ Period 2} & & & & & & \\
\hline & Micro & Small & Medium & Large & Total & & & & & & \\
\hline Entrant & .10 & .07 & .04 & .01 & .22 & & & & & & \\
\hline Micro & .10 & .04 & & & .14 & & & & & & \\
\hline Small & .02 & .16 & .04 & & .22 & & & & & & \\
\hline Medium & & .02 & .15 & .04 & .21 & & & & & & \\
\hline Large & & & .02 & .20 & .22 & & & & & & \\
\hline \multirow[t]{2}{*}{ Total } & .22 & .29 & .24 & .25 & & & & & & & \\
\hline & \multicolumn{5}{|c|}{ Period 3} & & \multicolumn{5}{|c|}{ Period 3} \\
\hline Period 1 & Micro & Small & Medium & Large & Total & Period 2 & Micro & Small & Medium & Large & Total \\
\hline Entrant & .15 & .18 & .08 & .03 & .43 & Entrant & .10 & .11 & .05 & .02 & .28 \\
\hline Micro & .05 & .04 & .01 & & .10 & Micro & .10 & .05 & .01 & & .16 \\
\hline Small & .02 & .09 & .04 & & .15 & Small & .02 & .14 & .04 & & .21 \\
\hline Medium & & .02 & .10 & .03 & .15 & Medium & & .02 & .13 & .01 & .17 \\
\hline Large & & & .03 & .14 & .17 & Large & & & .02 & .16 & .19 \\
\hline Total & .22 & .34 & .25 & .20 & & Total & .23 & .33 & .25 & .19 & \\
\hline
\end{tabular}

Note. Each panel contains the transition frequencies between two periods. 1-2 and 2-3 are 4 years apart; 1-3 8 years. The distribution of the "Total" row in panel 1-2 is not exactly equal to the "Total" column in panel 2-3 because each panel is calculated using firms active at the start and end of the respective period.

To compare with results for the United States, transition rates are also calculated between time periods of approximately equal length: 4-5 years. Baily et al. (1992) and Bartelsman and Dhrymes (1998) investigate transition rates between productivity quintiles or deciles for the United States. Both studies find substantial persistence in productivity. A third of the firms remain in the same quintile after 5 years, and a fifth of employment remains in the same productivity quintile even after 10 years. Table 8 contains the comparable transition probabilities between size classes for the African firms. Results for productivity quartiles are in table $9 .{ }^{19}$

The first thing to note is that in Africa transitions between size classes are extremely rare. Three-quarters of firms remain in their initial size category after 4 years, and even after 8 years two-thirds are still in the same category. Transitions between productivity quartiles are only slightly more common. Over 4-year intervals $59 \%$ of firms remain in the same quartile; this is still $53 \%$ over 8 years.

Moreover, the probability that a firm remains in the same size category is strongly increasing with firm size. For the 8 -year transition period, quadrant $1-3$ at the bottom left of table 8 , a full $70 \%$ of all large firms at the end, were already large at the beginning. For medium firms this is $40 \%$, and for small and micro firms, respectively, $26 \%$ and $23 \%$. Over shorter transition

19 Table B1 in app. B indicates the exact years used for each country. 
TABLE 9

TRANSITIONS BETWEEN PRODUCTIVITY QUARTILES OVER 4- AND 8-YEAR INTERVALS (PERCENTAGES)

\begin{tabular}{|c|c|c|c|c|c|c|c|c|c|}
\hline (LP) & \multicolumn{4}{|c|}{ Period 2} & & & & & \\
\hline Period 1 & $\leq 25 \%$ & $26 \%-50 \%$ & $51 \%-75 \%$ & $\geq 76 \%$ & & & & & \\
\hline Entrant & .07 & .05 & .05 & .06 & & & & & \\
\hline$\leq 25 \%$ & .12 & .04 & .01 & & & & & & \\
\hline $26 \%-50 \%$ & .05 & .09 & .04 & .01 & & & & & \\
\hline $51 \%-75 \%$ & .01 & .05 & .11 & .03 & & & & & \\
\hline \multirow[t]{2}{*}{$\geq 76 \%$} & & .02 & .04 & .14 & & & & & \\
\hline & \multicolumn{4}{|c|}{ Period 3} & & \multicolumn{4}{|c|}{ Period 3} \\
\hline Period 1 & $\leq 25 \%$ & $26 \%-50 \%$ & $51 \%-75 \%$ & $\geq 76 \%$ & Period 2 & $\leq 25 \%$ & $26 \%-50 \%$ & $51 \%-75 \%$ & $\geq 76 \%$ \\
\hline Entrant & .14 & .11 & .09 & .13 & Entrant & .10 & .08 & .06 & .09 \\
\hline$\leq 25 \%$ & .07 & .04 & .02 & & $\leq 25 \%$ & .10 & .04 & .02 & .01 \\
\hline $26 \%-50 \%$ & .02 & .06 & .04 & .01 & $26 \%-50 \%$ & .03 & .08 & .05 & .01 \\
\hline $51 \%-75 \%$ & .01 & .02 & .07 & .03 & $51 \%-75 \%$ & .01 & .03 & .09 & .04 \\
\hline$\geq 76 \%$ & .01 & .01 & .03 & .08 & $\geq 76 \%$ & & .01 & .03 & .12 \\
\hline
\end{tabular}

Note. Each box contains the transition frequencies between labor productivity quartiles for the same period pairs as above. The "Total" row and columns are omitted as they assign firms equally to each quartile, by construction. The number of firms is slightly lower and the share of entrants slightly higher than in table 8 , because of missing VA data.

periods, the decreased mobility by firm size becomes even more pronounced. The average probability a firm remains in the same category over a 4-year transition period is $82 \%$ for large firms, decreasing to $58 \%$ (medium), $49 \%$ (small), and $44 \%$ (micro).

Partly, surviving firms tend to grow larger over time and gradually move up in the classification. Fifteen percent of existing firms manage to grow to a larger category over the 4 -year transitions, and $21 \%$ do so over 8 years. Shrinking to a smaller category is only half as likely: $8 \%$ and $12 \%$ of firms. However, organic growth only gets a firm so far. A negligible share of micro or small firms grows to the large category even over 8 years. Even crossing the 25-employee threshold for medium size is relatively rare. Only $10 \%$ of micro firms manage that feat over 8 years and hardly any over 4 years. Medium firms are almost equally likely to shrink to small size as to grow to large size.

Entry of larger firms, on the other hand, is more common than smaller firms growing large. While the bulk of entrants start out as micro or small firms, as in developed countries, some start out large. In fact, entering as a large or medium firm is equally common as transitioning to large or medium size from all smaller size classes combined. Once firms are large, they tend to stay large. We do not observe any large firm dropping below medium size in table 8 .

For the transitions between labor productivity quartiles the "Total" rows and columns have been omitted, because firms are by construction spread 
equally over the four categories. The large persistence in the distribution$53 \%$ of survivors remain in the same category after 8 years-has been noted earlier. It is especially common for the most productive firms to remain in the same productivity quartile. They are more than twice as likely to remain in the top quartile as to go down. The same holds at the bottom of the productivity distribution: firms are more than twice as likely to remain in the bottom category as to move up.

It is especially interesting to look at the right-most column in each table. In each of the three transitions, more than $80 \%$ of the high-productivity firms at the end of each period were already at the top at the start or they entered during the period. Gradually improving productivity to break into the top rank is extremely rare. Only $2 \%$ of firms in the bottom half of the distribution manage to do this, and only slightly more of the firms in the $50 \%-75 \%$ bracket. More than half of firms that are in the top quartile at the end of the sample period did not exist 8 years earlier.

Transition dynamics between size categories and productivity quartiles indicate that the group of large or productive firms is very hard to break into. Firms are equally or even more likely to start out as large firms or at the top of the productivity distribution than to gradually make their way to the top. How the resource allocation reinforces the dominance of large and productive firms will be studied next.

\section{A Closer Look at Factor Markets}

\section{A. Labor Market}

Controlling for initial size or initial productivity level, large firms tend to grow relatively faster and improve productivity at faster rates. It is no surprise then that large firms are crucially important for the aggregate growth rate. Decomposing aggregate productivity growth, we gain further insights in the relative contribution of different size classes and how the reallocation of labor input between firms affects aggregate growth.

Defining the aggregate productivity level as $\mathrm{LP}_{t}=\sum_{i} \theta_{i t} \ln \mathrm{LP}_{i t}$ and aggregate productivity growth as $\Delta \ln \mathrm{LP}_{t}=\ln \mathrm{LP}_{t}-\ln \mathrm{LP}_{t-1}$ allows a straightforward decomposition in additive effects. Previous implementations for TFP have often used output shares. For LP it is more intuitive to use labor shares, because the employment-weighted average of firm-level productivity sums to the labor productivity for the total economy. Changes in weight will directly reflect relative employment changes.

The first decomposition (results are in table 10) illustrates the importance 
TABLE 10

DECOMPOSITION OF AGGREGATE LABOR PRODUCTIVITY GROWTH BY FIRM SIZE (1990-95)

\begin{tabular}{|c|c|c|c|c|c|c|c|c|c|c|}
\hline & \multicolumn{5}{|c|}{ Years of Positive Aggregate LPG } & \multicolumn{5}{|c|}{ Years of Negative Aggregate LPG } \\
\hline & Micro & Small & Medium & Large & Total & Micro & Small & Medium & Large & Total \\
\hline Ethiopia & & & & & & .009 & .026 & .153 & -.276 & -.088 \\
\hline Tanzania & .026 & .041 & .039 & -.006 & .100 & .019 & .072 & .004 & -.225 & -.130 \\
\hline Zambia & .007 & .012 & -.076 & .070 & .014 & .015 & .053 & .079 & -.225 & -.079 \\
\hline Kenya & .003 & .006 & -.026 & .071 & .055 & .002 & -.006 & -.027 & -.063 & -.095 \\
\hline Côte d'Ivoire & .003 & .021 & -.000 & .575 & .599 & .013 & .038 & -.020 & -.116 & -.085 \\
\hline Ghana & .061 & .087 & -.121 & .171 & .298 & .065 & .124 & .113 & -.407 & -.105 \\
\hline Zimbabwe & .001 & .004 & .008 & .017 & .030 & .003 & .003 & .010 & -.165 & -.148 \\
\hline Cameroon & .006 & .022 & -.003 & .063 & .089 & & & & & \\
\hline
\end{tabular}

of large firms. ${ }^{20}$ The contribution of each size class is aggregated separately, for example, the term labeled "Large" is

$$
\text { Large }=\sum_{j} \theta_{j t}^{L} \ln \mathrm{LP}_{j t}-\theta_{j t-1}^{L} \ln \mathrm{LP}_{j t-1},
$$

where $j$ indexes all large firms. The first five columns show, for each country, the average year-on-year growth rates for all years between 1990 and 1995 with positive aggregate productivity growth. Years with negative growth are averaged separately in the last five columns. ${ }^{21}$

With the sole exception of Tanzania, large firms are responsible for the bulk of aggregate growth. This is a combination of large firms increasing their relative employment share, $\Delta \theta_{i t}^{L}>0$, as well as firm-level productivity growth, $\Delta \ln \mathrm{TFP}_{i t}>0$. The aggregate growth experience, positive or negative, coincides with the experience of large firms (except for 1 year in Tanzania).

Interestingly, if large firms post a productivity decline, aggregate productivity declines by less, except for Kenya. A bad performance by large firms is rarely replicated by the smaller firms in the sample. While large firms are clearly important, micro and small firms make consistent positive, albeit small, contributions to aggregate growth. All but one of their 28 entries in table 10 is positive, even though large firms often post large productivity declines.

Because the share of micro and small firms in the manufacturing sector in these countries exceeds their share in the sample, their contribution to aggregate productivity growth could be much larger. For example, Mead (1994) calculates that micro and small firms are responsible for $40 \%$ of employment growth in

\footnotetext{
${ }^{20}$ The stratification by size in the sample does not allow an extrapolation of the results in table 10 to the aggregate manufacturing sector.

${ }^{21}$ Burundese firms had to be dropped because the only year prior to the survey period for which data on at least a quarter of firms is available is 1986 .
} 
TABLE 11

DECOMPOSITION OF AGGREGATE LABOR PRODUCTIVITY GROWTH: WITHIN, BETWEEN, AND COVARIANCE TERMS

\begin{tabular}{lcccccrrrr}
\hline & \multicolumn{3}{c}{ Years of Positive Aggregate LPG } & & \multicolumn{3}{c}{ Years of Negative Aggregate LPG } \\
\cline { 2 - 3 } & Within & Between & Covariance & Total & & Within & Between & Covariance & Total \\
\hline Ethiopia & & & & & & -.103 & .084 & -.069 & -.088 \\
Tanzania & .122 & .013 & -.036 & .100 & -.068 & -.009 & -.052 & -.130 \\
Zambia & .050 & .004 & -.039 & .014 & -.100 & .041 & -.020 & -.079 \\
Kenya & .245 & .155 & -.346 & .055 & -.066 & -.006 & -.023 & -.095 \\
Côte d'Ivoire & .593 & .044 & -.038 & .599 & -.073 & .031 & -.043 & -.085 \\
Ghana & .154 & .129 & -.085 & .198 & -.159 & .063 & -.009 & -.105 \\
Zimbabwe & .049 & .010 & -.029 & .030 & -.132 & -.002 & -.014 & -.148 \\
Cameroon & .129 & -.023 & -.016 & .089 & & & & \\
\hline
\end{tabular}

a number of African countries. However, the omission of unsuccessful entrants (see n. 18) is sure to overstate the positive contribution of smaller firms.

In the next decomposition (results are in table 11), share changes are separated from firm-level changes. Productivity growth at individual firms, a within effect, is a first factor that can increase the aggregate productivity level. Even if no firms experience positive productivity growth, the aggregate will improve if employees are relocated from firms with below average productivity to firms operating at higher productivity levels, a between effect. Efficient factor markets are expected to put resources to their most productive use. Finally, firms that increase employment might not be able to maintain their former level of labor productivity. The covariance between changes in employment share and productivity growth is the third term in the decomposition.

Baily et al. (1992) were the first to carry out such a decomposition and concluded that the contribution of the within term was minor for the United States. Haltiwanger (1997) modified the exercise to separate the between and the covariance terms and decomposed aggregate productivity as follows:

$$
\begin{aligned}
\Delta \ln \mathrm{LP}_{t}= & \sum_{i} \underbrace{\Delta \theta_{i t-1} \ln \mathrm{LP}_{i t} .}_{\text {within }} \\
& +\sum_{i} \underbrace{\Delta \theta_{i t}\left(\ln \mathrm{LP}_{i t-1}-\ln \mathrm{LP}_{t-1}\right)}_{\text {between }} \\
& +\sum_{i} \underbrace{\Delta \theta_{i t} \Delta \ln \mathrm{LP}_{i t} .}_{\text {covariance }}
\end{aligned}
$$

This revealed the importance of the covariance term and turnover, which can only be studied using the universe of firms. ${ }^{22}$ Levinsohn and Petrin (1999)

\footnotetext{
${ }^{22}$ We limit the sample to a balanced panel and do not include the effects of firm turnover. Because our sample is a survey, the interpretation of exit and, especially, entry is different from most previous analyses that have worked with a census, covering the entire universe of firms.
} 
found for Chile that increases in aggregate TFP are mostly the result of relocation of resources, while decreases are driven by firm-level changes.

In marked contrast, results for the African sample in table 11 point to the importance of firm-level changes. The within terms by themselves are responsible for almost the entire aggregate growth, independent of the aggregate growth experience. ${ }^{23}$ The effects of the between and covariance terms are generally opposite and approximately cancel out in many cases. Often the within term overshoots the aggregate and the other two terms temper the aggregate change. Where the sum of the other two terms works in the same direction, the within effect by itself accounts on average for $80 \%$ of the aggregate growth. Combined with the results in table 10, this points strongly to the importance of firm-level growth by large firms.

While firm-level growth is clearly important, the between effect also makes a positive contribution, even if the aggregate growth experience is negative. On average, the relocation of workers from low to high productivity firms adds $3.8 \%$ to aggregate productivity. The labor markets seem to do a good job putting workers to their most productive use.

Finally, the covariance term is strongly negative. ${ }^{24}$ Highly productive firms attract more workers, but this tends to depress their labor productivity level. Similarly, less productive firms that lower their employment share tend to increase labor productivity. This indicates that changes in output, positive or negative, are dominated by input changes. A potential explanation is that output changes predate input changes. Firms hire more workers only after they increase output, with smaller further increases. Workers might get fired after the bulk of the sales declines has already taken place.

\section{B. Capital Market}

Smaller firms are often thought to have difficulty accessing credit markets. The inability to tap into capital markets or the high price of capital they face leads them to operate with much less capital per worker than larger firms. As a result, Bigsten et al. (2000) find that the return to physical capital investments largely exceeds that of human capital.

Table 12 lists for a number of problems how often owners cite it as "The most important problem facing my business." Lack of credit is clearly the single most important issue. The majority of owners list it among the three most important problems, trumping all other concerns. Both the cost and

${ }^{23}$ Griliches and Regev (1995) find a similar, but less pronounced, effect of firm-level growth on aggregate labor productivity growth in Israel.

${ }^{24}$ Using output shares instead of input shares to weigh firms will generally lead to a positive covariance term, almost by construction. 
TABLE 12

BIGGEST PROBLEMS THE FIRMS FACE

\begin{tabular}{lcc}
\hline & $\begin{array}{c}\text { Frequency as the } \\
\text { Top Problem }\end{array}$ & $\begin{array}{c}\text { Frequency in Top Three } \\
\text { of Problems }\end{array}$ \\
\hline Lack of credit & .36 & .51 \\
Insufficient demand & .16 & .29 \\
Difficulty obtaining raw materials & .07 & .16 \\
Competition from imports & .06 & .12 \\
Taxes & .05 & .14 \\
Infrastructure & .05 & .15 \\
Utility prices & .02 & .10 \\
\hline
\end{tabular}

Note. Frequencies are calculated based on responses by owners/managers to a survey question.

availability of credit are problematic. The second problem identified by owners is lack of demand. What this covers in practice is less clear, but it might be a sign of too little price flexibility or producing the wrong products. This lack of demand is reinforced by the scarcity of credit, and it forces firms to award their credit-constrained clients some form of trade credit. Fafchamps (1997) documents the process and highlights the frequent instances of late or nonpayment. Van Biesebroeck (2003) illustrates that exporting can provide a solution by expanding the potential market and guaranteeing repayment of trade credit using a bill of lading.

The difficulty of obtaining raw materials, ranked as the third problem, is often caused by scarcity or the cost of foreign exchange. Opening up the economy can lessen this problem but exacerbate the next one, competition from imports. The last three problems, taxes, bad infrastructure, and utility prices, are more familiar complaints for developing countries, but it might come as a surprise that they do not figure higher on the list.

Kochar (1997) stresses that one should not ignore informal sources of credit to assess the financial rationing of firms. Table 13 shows how important the different sources of credit are in our sample. Ranked by decreasing degree of formality, these are loans, bank overdrafts, informal loans, and credit groups. ${ }^{25}$ On average, two-thirds of firms have access to some sort of credit. This varies between countries, from barely 38\% in Tanzania to more than $80 \%$ in Cameroon and Zimbabwe. The last two are, not coincidentally, the two most developed economies in the sample. Overdrafts are the most prevalent form of credit, and credit groups the least widespread. Only in Cameroon and Ethiopia do a significant fraction of firms rely on credit groups, and even if firms do, the amounts

${ }^{25}$ A credit group is an informal cooperation of a number of firms to pool resources and finance projects internally within the group. They have different names in each country and are generally established explicitly to deal with the difficulty of micro enterprises to secure more formal forms of credit. 
TABLE 13

ACCESS TO DIFFERENT FORMS OF CREDIT

\begin{tabular}{|c|c|c|c|c|c|c|c|c|c|}
\hline & \multicolumn{5}{|c|}{ Frequency of Obtaining Credit } & \multicolumn{4}{|c|}{ Size of Credit (\% of Sales) } \\
\hline & $\begin{array}{c}\text { Any } \\
\text { Credit }\end{array}$ & Loan & Overdraft & $\begin{array}{l}\text { Informal } \\
\text { Loan }\end{array}$ & $\begin{array}{l}\text { Credit } \\
\text { Group }\end{array}$ & Loan & Overdraft & $\begin{array}{l}\text { Informal } \\
\text { Loan }\end{array}$ & $\begin{array}{l}\text { Credit } \\
\text { Group }\end{array}$ \\
\hline Average & .67 & .31 & .45 & .21 & .13 & .33 & .17 & .26 & .01 \\
\hline Micro & .46 & .08 & .07 & .29 & .22 & .60 & .18 & .30 & .01 \\
\hline Small & .57 & .21 & .27 & .25 & .17 & .40 & .25 & .23 & .01 \\
\hline Medium & .76 & .37 & .61 & .17 & .08 & .38 & .17 & .30 & .01 \\
\hline Large & .90 & .56 & .84 & .13 & .04 & .24 & .14 & .16 & .00 \\
\hline
\end{tabular}

are smaller, as can be seen from the last column in table 13. As a percentage of sales, loans are the most important source of credit.

The difficulty of obtaining credit does not affect all firms equally. Less than half of micro enterprises have access to any form of credit, and informal loans or credit groups are by far the sources most commonly available to them. Less than $10 \%$ of micro firms have access to a loan and/or a bank overdraft. At the other extreme, almost all large firms have access to a secure source of credit. More than half have outstanding formal loans, and most have a bank overdraft as well. The amount of credit outstanding as a percentage of sales is only slightly higher for smaller firms. Moreover, the amounts are largest for loans, the category where the size advantage is the largest. Taking both availability and size of credit into account, $90 \%$ of all credit in our sample goes to large firms, $7 \%$ to medium firms, $1 \%$ to small firms, and only $0.1 \%$ to micro enterprises. This distribution is even more skewed toward larger firms than the employment distribution.

Even though large firms absorb most of the available credit, this is not necessarily bad policy by the lending agents given the superior performance by large firms documented earlier. If credit flows to firms with the best prospects and ability to serve and repay the debt, one could argue that the credit sector is serving its purpose. The high productivity levels, growth rates, and probability of survival of large firms makes them attractive borrowers.

Table 14 confirms that the allocation of credit is not at odds with productivity levels or growth. The table contains the coefficient estimates and standard errors on lagged labor and total factor productivity from different probit regressions. For each form of credit as dependent variable four probit regressions are run separately controlling for country, industry, and time. Size dummies are included to control for the distribution of credit by firm size already documented in table 13 .

Results in the first column indicate that firms receiving any credit have significantly higher productivity levels. They also tend to have slightly higher 
TABLE 14

PREDICTING ACCESS TO CREDIT

\begin{tabular}{lccccc}
\hline & Any Credit & Loan & Overdraft & Informal Loan & Credit Group \\
\hline$L P_{i t-1}$ & $.133^{\star \star \star}$ & $.098^{\star \star \star}$ & $.273^{\star \star \star}$ & $-.032^{\star}$ & $-.079^{\star \star \star}$ \\
& $(.019)$ & $(.021)$ & $(.022)$ & $(.020)$ & $(.028)$ \\
$T F P_{i t-1}$ & $.045^{\star \star}$ & $-.080^{\star \star \star}$ & $.086^{\star \star \star}$ & .006 & $.073^{\star \star}$ \\
& $(.023)$ & $(.026)$ & $(.026)$ & $(.025)$ & $(.036)$ \\
$L P G_{i t-1}$ & .043 & .053 & -.016 & -.017 & .077 \\
& $(.035)$ & $(.040)$ & $(.039)$ & $(.040)$ & $(.054)$ \\
$T F P G_{i t-1}$ & .022 & -.048 & .037 & -.016 & $.085^{\star}$ \\
& $(.035)$ & $(.035)$ & $(.037)$ & $(.040)$ & $(.054)$ \\
\hline
\end{tabular}

Note. Each coefficient is estimated by a separate Probit regression with country-year, sector, and size dummies as controls.

* Significant at the $10 \%$ level.

$\star \star$ Significant at the $5 \%$ level.

$\star \star \star$ Significant at the $1 \%$ level.

productivity growth rates, although those coefficients are not significantly different from zero. Point estimates for LP are much higher than for TFP, even though the observed range is much wider for the latter. Firms with easier access to credit are likely to operate with more capital, which raises LP, but not TFP. Given that credit availability is highly persistent over time, the direction of causation can go either way. Firms with high productivity might be more likely to have access to credit, or credit might raise productivity through capital accumulation.

The results for the different forms of credit reveal some interesting patterns. The two formal sources of credit, loans and overdrafts, are strongly associated with high levels of LP, but much less so with TFP. Formal loans even tend to go to firms with below average productivity, controlling for size. For the two informal sources, informal loans and credit groups, the results are opposite. Firms with high LP are less likely to secure these forms of credit, but they are awarded to firms with high TFP levels. The reverse causation discussed earlier-easy access to credit raises capital, while credit-constrained firms are forced to operate with less capital—seems at work here.

Smaller and low productivity firms are significantly less likely to receive financing. Credit groups fill a void left by the formal credit institutions, by focusing on the more productive of the micro and small enterprises. Firms that receive financing from credit groups not only have high levels of TFP, they also enjoy faster productivity growth. The point estimates on the two productivity growth measures are the largest by far for this form of credit.

Funds obtained from this source are not necessarily as small as the numbers in table 13 suggest. Firms are often able to roll over credit easily; in some cases no interest is paid, and funds merely provide financing to overcome 
liquidity problems; often the money is disbursed in monthly installments which makes the average amounts obtained as a percentage of annual sales, the statistic in table 13 , look very small.

While credit groups seem at least as able as formal credit institutions to award financing to the best performing firms, the same does not hold for informal loans. These loans are obtained from family or friends or from suppliers or clients, but they are not tied to specific transactions. There is no positive correlation between any measure of productivity for this form of credit. It provides source of funding outside the formal and informal credit sector and seems the source of last resort for ill-performing firms.

\section{Conclusions}

The presence of many micro and small firms in developing countries has often led researchers and multinational institutions to focus even more on smaller firms than policy makers in more developed economies. The employment creation and high growth rates of new entrants sometimes justify such attention. In contrast, the results for nine sub-Saharan countries in this article illustrate the superior performance of large firms.

Firms employing 100 or more workers are shown to be more productive and more likely to survive, which is in line with results for more developed countries. However, large firms also grow more rapidly and improve productivity faster, conditional on other covariates or on previous performance. Moreover, transitions between size classes or movements in the productivity distribution are very slow, especially at the top of the size or productivity distribution. Large firms remain large, and more productive firms remain at the top of the distribution. Smaller and less productive firms have a very hard time advancing in the size or productivity distribution.

The labor markets manage to relocate workers from less to more productive firms, and capital markets allocate credit to more productive firms. In both cases, this means that large and productive firms absorb ever more resources. While micro and small firms invariably make a positive contribution to aggregate labor productivity growth, the evolution of aggregate productivity growth is largely determined by the performance of large firms. Credit groups allow highly productive or up-and-coming small firms some access to credit. As the amount of financing available is smaller than through formal loans or overdraft accounts, it is no surprise that lack of credit is a persistent problem, especially for smaller firms. 


\section{Appendix A}

\section{Business Cycles}

Figure A1 plots GDP per capita (the lines without circles) and the index of real manufacturing output (with circles) for all countries. The scale on the right refers to GDP per capita and is the same for all countries. It trends up continuously for all countries, except for Cameroon and Burundi, which experienced small declines at the end of the sample period.

Manufacturing output is normalized at 100 in 1990, and the scale is on the left. It traces the evolution of GDP per capita, but fluctuations are more pronounced. The countries with the most consistent positive growth rate tend to be the most prosperous in the region, underscoring the importance of manufacturing for economic development. Most of the analysis focuses on the period from 1990 to 1995, which is indicated by two vertical lines. In the circled years, at least one-quarter of the firms in the sample had nonmissing values for employment and output, making it possible to calculate labor productivity.

Four countries can be considered expansionary in the early 1990s. The experience of Kenya was the most positive, enjoying positive and sustained growth throughout most of the period. Ghana also experienced positive growth after the collapse and restructuring of its economy around 1980. Côte d'Ivoire grew steadily, although more strongly, in the period immediately prior to and following the 1990-95 interval. Burundi was growing early on but slid into chaos after the first interview year. ${ }^{26}$ In these four countries, aggregating firmlevel growth rates for output and employment in the sample match the aggregate growth rates relatively well.

Four countries experienced negative growth during most of the sample period. In Zambia there was a collapse of economic activity after a number of hyperinflation years. Ethiopia declined for most of the 1980s, losing almost half of its manufacturing output. The recession bottomed out in the (only) interview year. Cameroon experienced positive growth during the 1980s, but from 1988 onward the level of economic activity went downhill. Zimbabwe had a similar, but less extreme, experience as Cameroon. Sample firms in Cameroon and Ethiopia show on average positive, albeit low, growth of employment and sales. They seem to have recovered from the recession before the rest of the economy.

Finally, Tanzania's growth rate was volatile between 1985 and 1995 with little trend. Manufacturing output declined immediately prior to the sample

${ }^{26}$ The second and third rounds of interviews had to be canceled because of the turbulent events of 1993. 


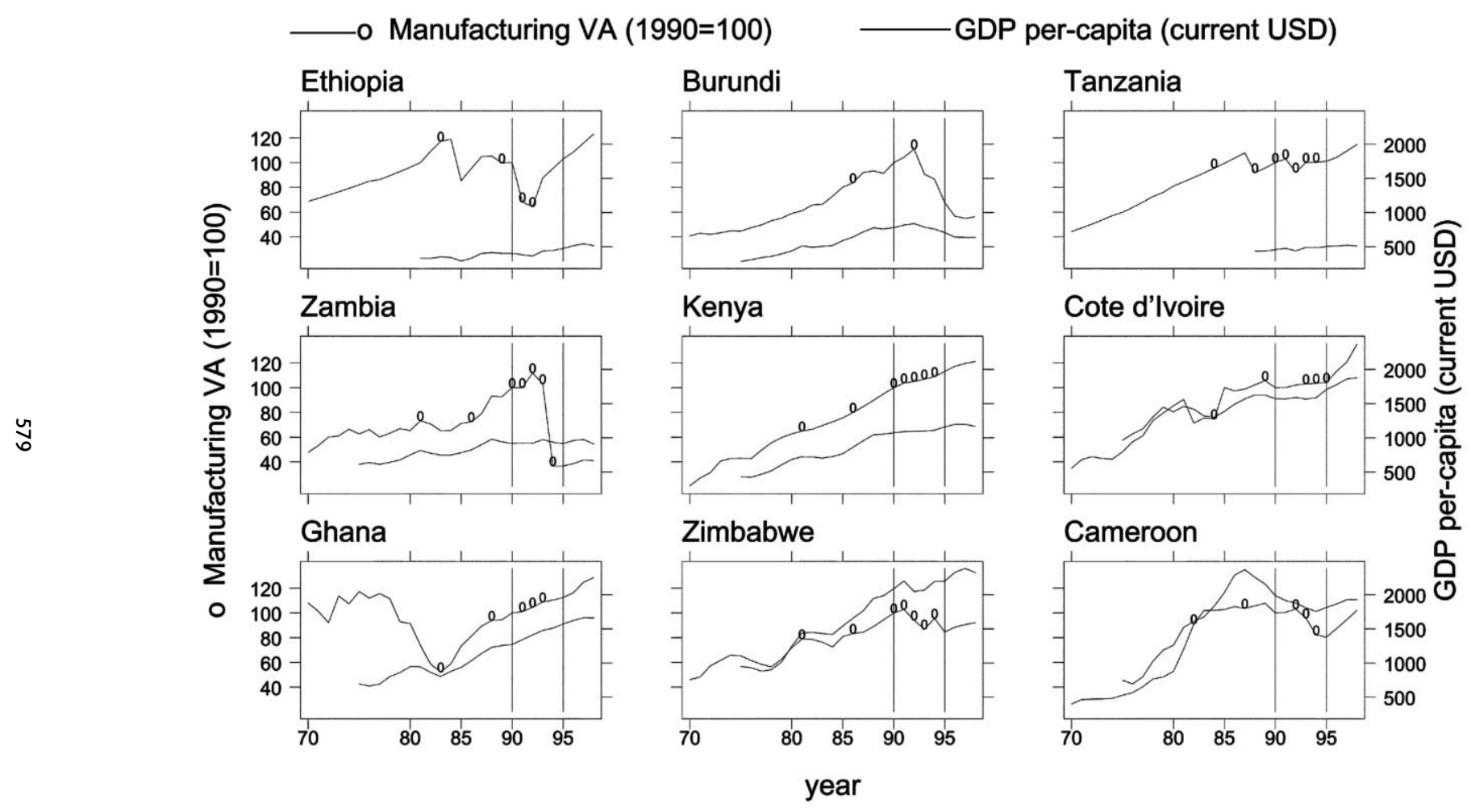

Figure A1. Aggregate growth: Real value added in manufacturing (left scale, $1990=100$ ) and GDP per capita (right scale, in U.S. dollars) 
ECONOMIC DEVELOPMENT AND CULTURAL CHANGE

TABLE B1

NUMBER OF OBSERVATIONS IN THE SAMPLE

\begin{tabular}{|c|c|c|c|c|c|c|c|c|c|}
\hline & Ethiopia & Burundi & Tanzania & Zambia & Kenya & $\begin{array}{c}\text { Côte } \\
\text { d'lvoire }\end{array}$ & Ghana & Zimbabwe & Cameroon \\
\hline 1981 & & & & 116 & 136 & & & 112 & \\
\hline 1982 & & & & & & & & & 69 \\
\hline 1983 & 114 & & & & & & 90 & & \\
\hline 1984 & & & 127 & & & 86 & & & \\
\hline \multicolumn{10}{|l|}{1985} \\
\hline 1986 & & 36 & & 164 & 163 & & & 153 & \\
\hline 1987 & & & & & & & & & 112 \\
\hline 1988 & & & 155 & & & & 122 & & \\
\hline 1989 & 160 & & & & & 138 & & & \\
\hline 1990 & & & 166 & 158 & 178 & & & 158 & \\
\hline 1991 & 197 & & 219 & 233 & 186 & & 193 & 189 & \\
\hline 1992 & 217 & 120 & 239 & 248 & 140 & & 195 & 199 & 232 \\
\hline 1993 & & & 206 & 228 & 141 & 192 & 190 & 203 & 216 \\
\hline 1994 & & & 148 & 194 & 218 & 235 & & 191 & 212 \\
\hline 1995 & & & & & & 225 & & & \\
\hline \multicolumn{10}{|l|}{ Unique } \\
\hline firms & 220 & 120 & 253 & 275 & 275 & 262 & 214 & 203 & 243 \\
\hline
\end{tabular}

Note. Bold numbers indicate three approximately equally spaced years chosen to calculate transition rates for each country.

period. Average growth for the Tanzanian firms in the sample is negative for employment and investment but positive for output.

\section{Appendix B}

\section{Number of Observations in the Sample}

Table B1 contains for each country and year the number of observations with nonmissing data for at least output and employment, necessary to calculate LP. Only years where at least one-quarter of the firms interviewed could be included are retained, the same years with circles in figure A1. Interviews were conducted in 1992, 1993, and 1994 for Ghana; in 1993 for Burundi and Ethiopia; in 1995 and 1996 for Côte d'Ivoire; and in 1993, 1994, and 1995 for all other countries. Most survey questions asked about economic activity in the year prior to the interview; for example, 1993 data were collected in 1994 interviews. Some recall questions asked about output, employment, sales, and investment in preceding years, with varying lags for different countries.

In each country, three (two in Burundi) approximately equally spaced years are chosen to calculate transition rates in Section IV.D, which are indicated in bold in table B1. When comparing two subsequent periods, only continuing firms, active in both the beginning and ending period, are taken into account.

\section{Appendix C}

\section{Robustness Check on the Distribution Results}

The regression results in table $\mathrm{C} 1$ verify the robustness of the findings pertaining to the size and productivity distributions in figures 2 and 3 and tables 
TABLE C1

DETERMINANTS OF SIZE AND PRODUCTIVITY

\begin{tabular}{|c|c|c|c|}
\hline & Employment & LP & TFP \\
\hline Small & & $\begin{array}{l}.397^{\star \star \star} \\
(.048)\end{array}$ & $\begin{array}{c}-.027 \\
(.074)\end{array}$ \\
\hline Medium & & $\begin{array}{l}.901^{\star \star \star} \\
(.050)\end{array}$ & $\begin{array}{l}.027 \\
(.077)\end{array}$ \\
\hline Large & & $\begin{array}{l}1.183^{\star \star \star} \\
(.055)\end{array}$ & $\begin{array}{l}.171^{\star} \\
(.085)\end{array}$ \\
\hline 2-5 years old & $\begin{array}{l}.192^{\star \star} \\
(.095)\end{array}$ & $\begin{array}{r}-.035 \\
(.083)\end{array}$ & $\begin{array}{c}-.186^{\star} \\
(.106)\end{array}$ \\
\hline 6-19 years old & $\begin{array}{l}1.015^{\star \star \star} \\
(.091)\end{array}$ & $\begin{array}{l}.009 \\
(.081)\end{array}$ & $\begin{array}{l}-.488^{\star \star \star} \\
(.101)\end{array}$ \\
\hline $20+$ years old & $\begin{array}{l}2.127^{\star \star \star} \\
(.096)\end{array}$ & $\begin{array}{l}.234^{\star \star \star} \\
(.087)\end{array}$ & $\begin{array}{c}-.280^{\star \star} \\
(.112)\end{array}$ \\
\hline Entrant & $\begin{array}{l}-.546^{\star \star \star} \\
(.106)\end{array}$ & $\begin{array}{c}-.186^{\star} \\
(.096)\end{array}$ & $\begin{array}{c}-.270^{\star} \\
(.145)\end{array}$ \\
\hline Exiting firm & $\begin{array}{c}-.177^{\star \star} \\
(.084)\end{array}$ & $\begin{array}{c}-.082 \\
(.074)\end{array}$ & $\begin{array}{c}-.240^{\star \star \star} \\
(.083)\end{array}$ \\
\hline Observations & 7,639 & 6,691 & 3,078 \\
\hline Adjusted $R^{2}$ & .245 & .144 & .196 \\
\hline
\end{tabular}

2, 3, and 4. The logarithm of, respectively, employment, LP, and TFP, is regressed on the same size, age, and life cycle categories as before. The outside categories are less than 2 years old, small firms.

\section{References}

Aw, Bee Y., Xiaomin Chen, and Mark J. Roberts. 2001. "Firm-Level Evidence on Productivity Differentials and Turnover in Taiwanese Manufacturing." Journal of Development Economics 66 (October): 51-86.

Baily, Martin N., Charles Hulten, and David Campbell. 1992. "Productivity Dynamics in Manufacturing Plants." Brookings Papers: Microeconomics 4, no. 1: $187-267$.

Bartelsman, Eric J., and Phoebus J. Dhrymes. 1998. "Productivity Dynamics: U.S. Manufacturing Plants, 1972-1986.” Journal of Productivity Analysis 9 (January): $5-34$.

Bartelsman, Eric J., and Mark Doms. 2000. "Understanding Productivity: Lessons from Longitudinal Microdata." Journal of Economic Literature 38 (September): 569-94.

Biggs, Tyler, and Pradeep Srivastava. 1996. "Structural Aspects of Manufacturing in Sub-Saharan Africa: Findings from a Seven Country Enterprise Survey.” World Bank Discussion Paper no. 346, Africa Technical Department Series, World Bank, Washington, DC.

Bigsten, Arne, Paul Collier, Stefan Dercon, Marcel Fafchamps, Bernard Gauthier, Jan W. Gunning, Anders Isaksson, Abena Oduro, Remco Oostendorp, Catherine Pattillo, Måns Söderbom, Francis Teal, and Albert Zeufack. 2000. "Rates of Return 
on Physical and Human Capital in Africa's Manufacturing Sector." Economic Development and Cultural Change 48 (July): 801-27.

Caves, Douglas W., Laurits R. Christensen, and Erwin W. Diewert. 1982. "The Economic Theory of Index Numbers and the Measurement of Input, Output, and Productivity." Econometrica 50 (November): 1393-1414.

Caves, Richard E. 1998. "Industrial Organization and New Findings on the Turnover and Mobility of Firms.” Journal of Economic Literature 36 (December): 1947-82.

Center for International Business Research. 1997. "Preliminary Report on the RPED Tanzania Survey.” Unpublished manuscript, Helsinki School of Economics.

Davis, Steven, John Haltiwanger, Ron Jarmin, C. J. Krizan, and Kristin Sandusky. 2004. "The Dynamics of Young Businesses." Unpublished manuscript, Center for Economic Studies, Bureau of the Census, Washington, DC.

Diewert, Erwin W. 1976. "Exact and Superlative Index Numbers." Journal of Econometrics 4 (May): 115-45.

Fafchamps, Marcel. 1997. "Trade Credit in Zimbabwean Manufacturing." World Development 25 (May): 798-815.

Frazer, Garth. 2004. "Which Firms Die? A Look at Exit from Manufacturing in Ghana." Unpublished manuscript, Rotman School of Management, University of Toronto.

Griliches, Zvi, and Jacques Mairesse. 1983. "Comparing Productivity Growth: An Exploration of French and U.S Industrial and Firm Data." European Economic Review 21 (March-April): 89-119.

Griliches, Zvi, and Haim Regev. 1995. "Firm Productivity in Israeli Industry: 1979-1988." Journal of Econometrics 65 (January): 175-203.

Haltiwanger, John C. 1997. "Measuring and Analyzing Aggregate Fluctuations: The Importance of Building from Microeconomic Evidence.” Federal Reserve Bank St. Louis Review 79 (May-June): 55-77.

Kochar, Anjini. 1997. "An Empirical Investigation of Rationing Constraints in Rural Credit Markets in India.” Journal of Development Economics 53 (August): 339-71.

Levinsohn, James, and Amil Petrin. 1999. "When Industries Become More Productive, Do Firms? Investigating Productivity Dynamics.” Working Paper no. 6899, National Bureau of Economic Research, Cambridge, MA.

Liedholm, Carl, and Donald C. Mead. 1999. Small Enterprises and Economic Development. Studies in Development Economics. New York: Routledge.

McPherson, Michael A. 1996. "Growth of Micro and Small Enterprises in Southern Africa." Journal of Development Economics 48 (March): 235-77.

Mead, Donald C. 1991. "Review Article: Small Enterprises and Development." Economic Development and Cultural Change 39 (January): 409-20.

1994. "The Contribution of Small Enterprises to Employment Growth in Southern and Eastern Africa." World Development 22 (December): 1881-94.

Mead, Donald C., and Carl Liedholm. 1998. "The Dynamics of Micro and Small Enterprises in Developing Countries.” World Development 26 (January): 61-74.

Ranis, Gustav. 1988. “Analytics of Development: Dualism.” In Handbook of Development Economics, vol. 1, ed. H. Chenery and T. Srinivasan. New York: NorthHolland. 
Roberts, Mark, and James R. Tybout. 1996. Industrial Evolution in Developing Countries. New York: Oxford University Press for the World Bank.

Sleuwaegen, Leo, and Marceline Goedhuys. 2002. "Growth of Firms in Developing Countries, Evidence from Côte d'Ivoire.” Journal of Development Economics 68 (June): 117-35.

Söderbom, Måns, and Francis Teal. 2004. "Size and Efficiency in African Manufacturing Firms: Evidence from Firm-Level Panel Data." Journal of Development Economics 73 (February): 369-94.

Tybout, James R. 2000. "Manufacturing Firms in Developing Countries: How Well Do They Do, and Why?” Journal of Economic Literature 28 (March): 11-44.

Tybout, James R., and Lily Liu. 1996. "Productivity Growth in Chile and Colombia: The Role of Entry, Exit, and Learning." In Industrial Evolution in Developing Countries, ed. M. Roberts and J. R. Tybout. New York: Oxford University Press for the World Bank.

Van Biesebroeck, Johannes. 2003. "Exporting Raises Productivity in Sub-Saharan African Manufacturing Firms." Working paper no. 10020, National Bureau of Economic Research, Cambridge, MA.

World Bank. 1997a. Africa South of the Sahara. http://www.worldbank.org/data/ onlinedatabases/onlinedatabases.html.

World Bank. 1997b. World Development Report. Washington, DC: World Bank. 